\title{
Identification of novel seed longevity genes related to oxidative stress and seed coat by genome-wide association studies and reverse genetics
}

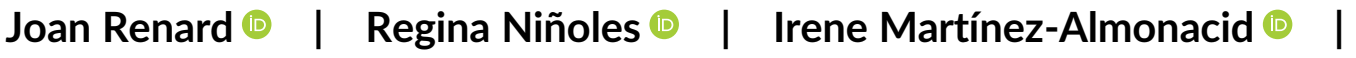

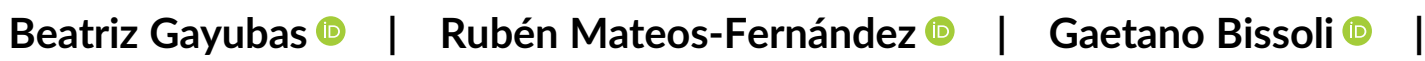

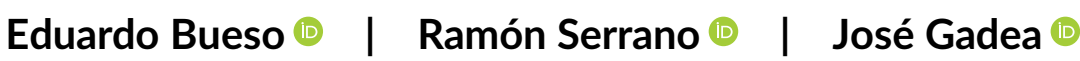

Instituto de Biología Molecular y Celular de Plantas (IBMCP), Universitat Politècnica de València-C.S.I.C., Valencia, Spain

\section{Correspondence}

José Gadea and Ramón Serrano, Instituto de Biología Molecular y Celular de Plantas (IBMCP), Universitat Politècnica de València-C. S.I.C., Camino de Vera, 46022, Valencia, Spain. Email: jgadeav@ibmcp.upv.es (J. G.) and Email: rserrano@ibmcp.upv.es (R. S.)

Funding information

Ministerio de Ciencia, Innovación y Universidades, Grant/Award Number: BIO2017-88898-P

\begin{abstract}
Seed longevity is a polygenic trait of relevance for agriculture and for understanding the effect of environment on the ageing of biological systems. In order to identify novel longevity genes, we have phenotyped the natural variation of 270 ecotypes of the model plant, Arabidopsis thaliana, for natural ageing and for three accelerated ageing methods. Genome-wide analysis, using publicly available single-nucleotide polymorphisms (SNPs) data sets, identified multiple genomic regions associated with variation in seed longevity. Reverse genetics of 20 candidate genes in Columbia ecotype resulted in seven genes positive for seed longevity (PSAD1, SSLEA, SSTPR, DHAR1, CYP86A8, MYB47 and SPCH) and five negative ones (RBOHD, RBOHE, RBOHF, KNAT7 and SEP3). In this uniform genetic background, natural and accelerated ageing methods provided similar results for seed-longevity in knock-out mutants. The NADPH oxidases (RBOHs), the dehydroascorbate reductase (DHAR1) and the photosystem I subunit (PSAD1) highlight the important role of oxidative stress on seed ageing. The cytochrome P-450 hydroxylase, CYP86A8, and the transcription factors, MYB47, KNAT7 and SEP3, support the protecting role of the seed coat during seed ageing.
\end{abstract}

\section{KEYWORDS}

accelerated ageing, Arabidopsis thaliana, CYP86A8, NADPH oxidases, natural variation, oxidative stress, reverse genetics, seed ageing, seed coat, seed longevity

\section{1 | INTRODUCTION}

Imperfections of metabolism result in accumulation of deleterious and damaged molecules that age cells and organisms (Gladyshev, 2014; López-Otín et al., 2016). According to the oxidative stress theory of ageing, a major metabolic reaction contributing to ageing is the production of reactive oxygen species (ROS) (Harman, 1956). Current views (López-Otín et al., 2016) consider that ageing is controlled by metabolism in a more general way than just ROS production. However, it has been argued that oxidative stress contributes to all the metabolic and genomic alterations associated with ageing (Schmidlin, Dodson, Madhavan, \& Zhang, 2019).

One model for the study of biological ageing is the seed of vascular plants. Ageing is slowed down in desiccated forms of organisms, where metabolism is reduced because of high viscosity and slow diffusion inside cells. Accordingly, desiccation is the mechanism developed by many life forms to decrease metabolism and endure for long times (Wood \& Jenks, 2008). Most organisms die upon desiccation and, therefore, acquisition of desiccation tolerance is a prerequisite for this longevity mechanism. In the case of plants, it has been suggested that the evolution of 
desiccation tolerance was a crucial step in the colonization of land by primitive plants living in fresh water (Oliver, Tuba, \& Mishler, 2000). Nowadays, very few plants (the so-called resurrection plants) are desiccation tolerant in their vegetative form. However, orthodox seeds are tolerant to desiccation, a feature acquired during their late maturation phase. This tolerance results from the accumulation of osmolytes (sucrose and raffinose family oligosaccharides [RFOs]), late embryogenesis abundant proteins (LEAs) and small heat shock proteins (Leprince, Pellizzaro, Berriri, \& Buitink, 2017; Sano et al., 2016). Under these conditions, cytoplasm enters an immobilized glassy state that protects macromolecules and cellular membranes during desiccation (Ballesteros \& Walters, 2011; Hoekstra, Golovina, \& Buitink, 2001; Leprince et al., 2017; Sano et al., 2016). This desiccated state of seeds permits to keep the plant alive for long periods of time, until environmental conditions are favourable. However, dry seeds also experience deterioration and ageing, and it has been proposed that oxidative damage is a major cause for reducing longevity in this system (Bailly, 2004; Harman \& Mattick, 1976; Nagel et al., 2019; Sano et al., 2016).

High temperature and humidity are deleterious for seeds because they break the glassy state and promote metabolism, and therefore ROS and cellular damage. Equilibrating mature seeds between 19 and $27 \%$ relative environmental humidity $\left(0.04-0.06 \mathrm{~g} \mathrm{H}_{2} \mathrm{O} / \mathrm{g}\right.$ dry weight in seeds) provides the optimum moisture level for reducing metabolism and maintaining seed longevity during long-term storage (Vertucci \& Roos, 1990). Seed deterioration occurs under ambient storage or natural conditions (about $20-25^{\circ} \mathrm{C}, 40-60 \%$ relative humidity [RH], 0.08-0.10 g H $\mathrm{g}_{2} \mathrm{O} / \mathrm{g}$ dry weight), where dried seeds still exhibit some metabolism.

Analysis of quantitative trait loci (QTLs) has demonstrated the polygenic nature of seed longevity in different plants, such as rice (Jiang et al., 2011), wheat (Landjeva, Lohwasser, \& Börner, 2010), lettuce (Schwember \& Bradford, 2010), tobacco (Agacka-Mołdoch, Nagel, Doroszewska, Lewis, \& Börner, 2015) and barley (Nagel et al., 2016). Several genes, important for seed longevity in the model plant, Arabidopsis thaliana, have been identified by reverse genetics and compiled by Sano et al. (2016). They refer to three biological functions: antioxidative defence, repair of damaged proteins and nucleic acids, as well as development of seed coat. Some important aspects that need to be clarified include the nature of the ROS producing systems and of antioxidant defences during seed storage, the protective mechanisms of the seed coat and the complete gene networks controlling seed longevity. Many antioxidant defences, such as enzymes and chemicals, have been proposed to participate in seed longevity but only vitamin $E$ (tocopherol) has been demonstrated to be important by mutant studies (Sattler, Gilliland, Magallanes-Lundback, Pollard, \& DellaPenna, 2004). Moreover, the seed coat has been proposed to be important, especially the endothelium flavonoids (proanthocyanidins; Clerkx, Blankestijn-De Vries, Ruys, Groot, \& Koornneef, 2004) and the palisade suberin (Bueso et al., 2014, 2016; Renard et al., 2020) but the transcription factors and enzymes involved in the development of this structure (Haughn \& Chaudhury, 2005) are not completely known.

In the present work, we took advantage of natural variation in seed longevity between accessions (ecotypes) of Arabidopsis thaliana with well- characterized genomes to perform a genome-wide association study (GWAS) of this trait. GWAS analysis is a powerful tool to dissect polygenic traits (Atwell et al., 2010; Korte \& Farlow, 2013) and Arabidopsis is an excellent organism for this purpose (Horton et al., 2012; Weigel, 2012). GWAS consists of the association of the molecular genetic information (single-nucleotide polymorphisms [SNPs]) with the observed variation in a given trait through statistical computation. These associations point to causal loci that may be involved in the trait and may explain part of the natural variation between accessions (Curtin et al., 2017). However, for each candidate gene in these loci, empirical validation is required due to the high number of false positives with this genomic approach (loannidis, Thomas, \& Daly, 2009; Korte \& Farlow, 2013). Arabidopsis is the most studied plant species at the molecular level and a large collection of sequence-indexed T-DNA insertion mutants is available (O'Malley \& Ecker, 2010). This valuable resource allows validation of GWAS candidate genes by testing the phenotype of the corresponding loss-of-function mutants in the same cultivar background.

As the study of seed longevity under natural, ambient storage conditions requires long times for ageing, several accelerated ageing procedures have been utilized in this field. The quickest is the accelerated ageing test (AAT), which consists of a high-temperature treatment of water imbibed seeds during days (Bueso et al., 2014; PrietoDapena, Castaño, Almoguera, \& Jordano, 2006). In the controlled deterioration test (CDT), ageing of dry seeds occurs in weeks with a high humidity and high temperature atmosphere. Finally, to target the oxygen-produced damage, there is the elevated partial pressure of oxygen test (EPPO), in which dry seeds are stored for months in a low humidity and high-pressured oxygen atmosphere (Groot, Surki, de Vos, \& Kodde, 2012; Hay, Valdez, Lee, \& Cruz, 2019; International Seed Testing Association, 2018). Although in some studies with few genotypes there is a similar behaviour in both natural and artificial ageing (Bueso et al., 2014; Rajjou et al., 2008), each ageing procedure might affect different physiological and molecular aspects of the seed deterioration-resistance trait. Accordingly, to increase the list of candidate genes, we have performed natural ageing and different artificial ageing treatments.

Our results suggest that the different tests used to evaluate seed longevity are highlighting different aspects of the machinery deployed by the seed to avoid deterioration. However, when seed longevity was determined in mutants from the same genetic background, natural and artificial ageing procedures gave similar results. Validation of candidate genes resulted in several novel participants in seed longevity, such as ROS-producing NADPH oxidases (RBOHs), antioxidant dehydroascorbate reductase and, related to seed coat development, a P450 cytochrome hydroxylase and several transcription factors (TFs).

\section{2 | MATERIALS AND METHODS}

\subsection{Plant material and growth conditions}

A core set of 360 Arabidopsis thaliana ecotypes was obtained from the Nottingham Arabidopsis Stock Centre (NASC) (reference 
N76309). All Ecotypes were grown simultaneously to obtain fresh seeds in homogeneous conditions. Seven plants of each ecotype were grown in $11-\mathrm{cm}$ diameter pots, containing a 1:2 vermiculitesoil mixture under growth chamber conditions (16 hr light/8 hr dark, at $16-23^{\circ} \mathrm{C}$ and $\left.70-75 \% \mathrm{RH}\right)$. T-DNA insertion lines in Col-0 background were obtained from NASC or kindly supplied by original authors (Table S1). Homozygous plants were obtained and confirmed by PCR. Some mutants were previously described: dhar1, dhar2, dhar3 and dhar1,2,3 (Rahantaniaina et al., 2017), rbohe (Xie, Wan, Li, \& Zhang, 2014), rbohd,f (Torres, Dangl, \& Jones, 2002), spch (MacAlister, Ohashi-Ito, \& Bergmann, 2007), knat7 (Romano et al., 2012), sep3 (Pelaz, Ditta, Baumann, Wisman, \& Yanofsky, 2000) and sep1,2,4 (Ditta, Pinyopich, Robles, Pelaz, \& Yanofsky, 2004). Control and mutant plants were grown simultaneously and seeds were collected and stored under same conditions.

\subsection{Artificial and natural ageing assays}

Seed ageing assays were performed simultaneously in all ecotypes. Seed sterilization consisted of $8 \mathrm{hr}$ chlorine gas treatment. One week of stratification $\left(4^{\circ} \mathrm{C}, 100 \% \mathrm{RH}\right)$ was used to ensure complete dormancy break. A control germination assay was used to discard ecotypes with affected germination and correct germination ratios. Selected ecotypes underwent three different artificial ageing treatments, whose specific conditions were prior adjusted with the Col-0 ecotype. The accelerated-ageing treatment (AAT) consisted of imbibing seeds in water and maintained at $39^{\circ} \mathrm{C}$ for $48 \mathrm{hr}$ (Prieto-Dapena et al., 2006). The controlled deterioration treatment (CDT) was set with 14 days at $38^{\circ} \mathrm{C}$ in a $75 \% \mathrm{RH}$ atmosphere (Righetti et al., 2015). The elevated partial pressure of oxygen (EPPO) was performed for 5 months at 5 bars $\mathrm{O}_{2}$ with a 40\% RH (Groot et al., 2012; Nagel et al., 2016). Natural seed ageing treatment (NAT) consisted of dry seed storage at room temperature $\left(20-25^{\circ} \mathrm{C}, 40-60 \% \mathrm{RH}\right)$ for 18 months. Except in AAT, all ageing treatments were performed prior to seed sterilization and stratification.

Arabidopsis ecotypes were sown on $25 \mathrm{ml}$ Murashige and Skoog (MS) plates, with sucrose, as described by Alejandro et al. (2007). Each plate was planted with 125 seeds on average. Germination ratios were scored after 7 days. Radicle extrusion and seedling establishment with green cotyledon were used as germination indicators. The number of established seedlings under our experimental conditions did not increase after 1 week. The corrected germination ratio was calculated by dividing the germination ratio in each treatment by the germination ratio in control conditions.

For seed longevity analysis in Arabidopsis mutant seeds, similar test conditions were used. Ethanol and bleach sterilizations were used. NAT time was adjusted to obtain maximum differences with Col-O seeds. Mutant lines were tested three times in two different seed generations in all different assays. Significant differences with control Col-0 were assessed by Student's $t$ test $(p<.05)$.

\section{3 | GWAS analysis}

All four GWAS were performed using the online application GWAPP (Seren et al., 2012). Corrected germination ratios were used as GWAPP input. Only NAT data were transformed logarithmically, for Shapiro-Wilk score and pseudo-heritability calculation. The dataset used for the GWAS was the imputed full sequence Dataset (Cao et al., 2011; Gan et al., 2011; Horton et al., 2012; Long et al., 2013). GWAS results were filtered by minor allele frequency $(\mathrm{MAF}) \geq 0.05$. Genes 1.5 kilobases (kb) up- and downstream of significant SNPs were mapped using TAIR10 (The Arabidopsis Information Resource version 10). The significance threshold in this study was set at $p$ value $\leq 10^{-5}$. The easyGWAS online tool (Grimm et al., 2017) was used to calculate Spearman correlations $\left(r_{s}\right)$ between our data and different public data. Strong direct correlations were considered if $r_{s} \geq 0.3$, and strong inverse correlation if $r_{s} \leq-0.3$.

\section{4 | In silico gene expression analysis}

Gene expression analysis was performed with the online tool eFP browser (Winter et al., 2007). Developing seed gene-expression was obtained from Le et al. (2010) data. Subcellular location information was obtained from Hooper, Castleden, Tanz, Aryamanesh, and Millar (2017) data.

\subsection{Seed analysis}

Mucilage staining of dry seeds was performed as described in Bueso et al. (2014). Proanthocyanidin (PA) staining in seeds was performed at 5 days-after-pollination (DAP), as described in Debeaujon, LéonKloosterziel, and Koornneef (2000). Lipid polyester barriers staining was performed as described in Brundrett, Kendrick, and Peterson (1991) and Beisson, Li, Bonaventure, Pollard, and Ohlrogge (2007), in dry seeds. Tetrazolium permeability assays were performed as described by Debeaujon et al. (2000). Size calculation was done with Fiji program (Schindelin et al., 2012).

\subsection{Construction of transgenic plants}

Primers used in this work are listed in Table S2. For expression analysis, $2 \mathrm{~kb}$ upstream MYB47 coding region was amplified from genomic DNA with proMYB47-F and proMYB47-R primers and inserted into the pCR8 plasmid by using the $\mathrm{pCR}^{\mathrm{TM}} 8 / \mathrm{GW} / \mathrm{TOPO}{ }^{\circledR}$ TA Cloning ${ }^{\circledR} \mathrm{Kit}$ from Thermo Fisher Scientific (Waltham, MA). LR reaction recombined our construct with the pMDC107 plasmid (Curtis \& Grossniklaus, 2003). For construction of over-expression lines, its coding sequence was amplified with MYB47-F and MYB47-R primers from cDNA, and cloned into $\mathrm{PCR} 8$ as before. The resulting plasmid was recombined with pUB-DEST plasmid (Grefen et al., 2010) by LR reaction. Agrobacterium C58, containing final plasmids, was used for plant transformation. $T_{3}$ homozygous plants and seeds were used to avoid genotype segregation. 


\section{$2.7 \quad$ Expression analysis}

Total RNA of knock-out mutant, myb47, and OE mutants of MYB47 was obtained from 7-day old seedlings with E.Z.N.A. Plant RNA Kit (Omega Bio-tek). Two microgram RNA was reverse transcribed using the Maxima first-strand cDNA synthesis kit for RT-qPCR (Thermo Fisher Scientific). Quantitative (real-time) PCR (qRT-PCR) was performed in triplicate using an Applied Biosystems 7,500 Real-Time PCR System (Thermo Fisher Scientific) with PyroTaq EvaGreen qPCR Mix Plus (ROX) (Cultek S.L.U., Madrid, Spain) and MYB47-qRT-F and MYB47-qRT-R primers (Table S2). Relative mRNA abundance of PP2AA3 was calculated using the comparative $\Delta \mathrm{Ct}$ method (Czechowski, Stitt, Altmann, Udvardi, \& Scheible, 2005).

\subsection{Confocal microscopy}

To visualize the driven-promotor GFP expression, a confocal ZEISSLSM710 microscope was used. The laser used was Argon with an excitation lambda of $488 \mathrm{~nm}$, and an emission spectrum of 500-550 nm was registered. Images were processed with Fiji program (Schindelin et al., 2012).

\section{$3 \mid$ RESULTS}

\section{1 $\quad$ CDT correlates best with natural ageing}

To elucidate new genetic components involved in seed longevity, a core-set of 360 Arabidopsis ecotypes was obtained from NASC to perform GWAS. All accessions were grown on soil under long-day conditions, and mature seeds were collected from all accessions that were able to flower and develop seeds in a time-window not wider than 160 days. Two hundred and seventy natural accessions were selected for ageing treatments after the control (non-aged) germination test (Data S1). Four different ageing methods were performed: natural ageing treatment (NAT) and three artificial ageing treatments (AAT, CDT and EPPO). Aged seeds germination data were corrected using control germination data (Data S2). A wide range of variability was observed among all the accessions in each of the different assays (Figures 1a,b,c,d). The accession Col-0 (Columbia), used as reference to set up all treatments, varied from 40 to $60 \%$ of germination in all treatments.

To estimate how each artificial ageing treatment resembles natural ageing, Spearman correlations were calculated (Figure 1e). CDT is the artificial ageing treatment correlating best with NAT $\left(r_{s}=0.68\right)$, followed by EPPO $\left(r_{s}=0.47\right)$. AAT does not correlate with NAT in this study $\left(r_{s}=0.11\right)$. AAT is the quickest (days) artificial ageing method used and at variance with other treatments, it involves immersion of seeds into water.

We next calculated correlations with public datasets and ecotype collection data. Although the coincidental ecotypes with our collection were small in most cases (48-83 ecotypes), an inverse correlation between seed longevity and flowering time, rosette leaf number and plant life span could be observed (Table 1). These three traits are linked and suggest the importance of early flowering for seed longevity. There is also an inverse correlation of iron content in leaves with NAT, CDT and EPPO. No correlation was found with seed dormancy, latitude of collection point or anthocyanin content, among others. All other correlations with public datasets are listed in Data S3.

\section{2 | The different seed ageing treatments highlight multiple genomic areas and candidate genes}

The corrected germination data obtained after each ageing treatment (Data S2) were used to perform four different GWAS analyses, one for each seed ageing treatment. Results can be visualized at https:// gwas.gmi.oeaw.ac.at/\#/study/5406/overview. We established a relaxed $p$ value $\left(<10^{-5}\right)$ threshold to consider putative longevityrelated genomic areas (Figure 2). Genes enclosed within the $1.5 \mathrm{~kb}$ region spanning significant SNPs were listed (Data S4). Natural ageing (NAT) highlighted 99 genes, the AAT treatment, 280 genes, the CDT, 130 genes and the EPPO, 337 genes. We further filtered for candidate genes following three criteria: (a) biological function based on the state-of-knowledge (Sano et al., 2016); (b) gene expression during seed development (Le et al., 2010; compiled in Figures S1 and S2); and (c) distance to highly scored SNPs. Occasionally, few genes with $p$ values slightly above $10^{-5}$ were considered for reverse genetic analysis. In some cases, gene family members from candidate genes were also selected. For validation and further experimentations, double and triple mutants were obtained. Table 2 shows the list of candidate genes selected for reverse genetic analysis in this study.

\section{3 | T-DNA insertion mutants identify novel genes involved in seed longevity}

Three different seed lots of two different plant generations from every mutant line were aged with two artificial treatments (AAT and CDT; Table 3) and with natural conditions (NAT). Figure 3 describes three seed ageing sensitive mutants: a late embryogenesis abundant (LEA) protein (AT3G17520), a subunit of photosystem I (PSAD1), and a tetratricopeptide repeat (TPR) protein (AT4G02750). The LEA and TPR genes were named SSLEA and SSTPR, with SS meaning seed storability. PSAD1 and SSTPR were highlighted by two and three artificial ageing treatments, respectively (Table 2 ). After 18 months of natural ageing, all three mutant seeds present a drastic reduction of germination. PSAD1 and LEA are expressed in mature embryos, while SSTPR is expressed in developing embryos (Figure S1; Le et al., 2010). As indicated in Table 3, mutants in these three genes also exhibited reduced seed longevity with two artificial ageing treatments (AAT and CDT). Mutant sstpr seeds present an increased tetrazolium reduction (Figure S3) indicating greater seed coat permeability. 
(a)

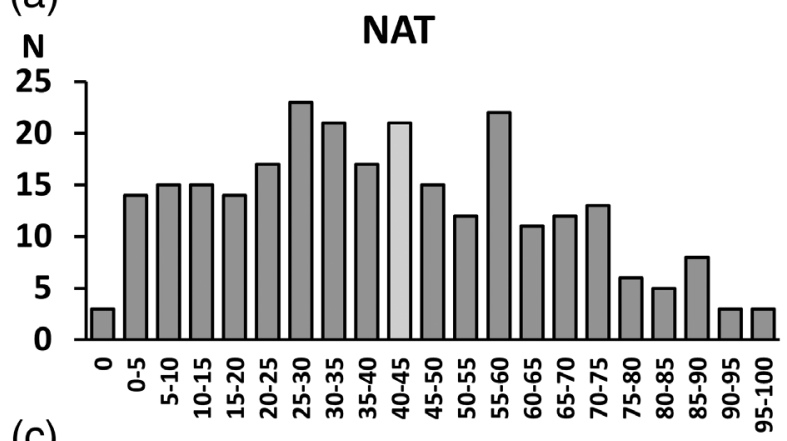

(c)

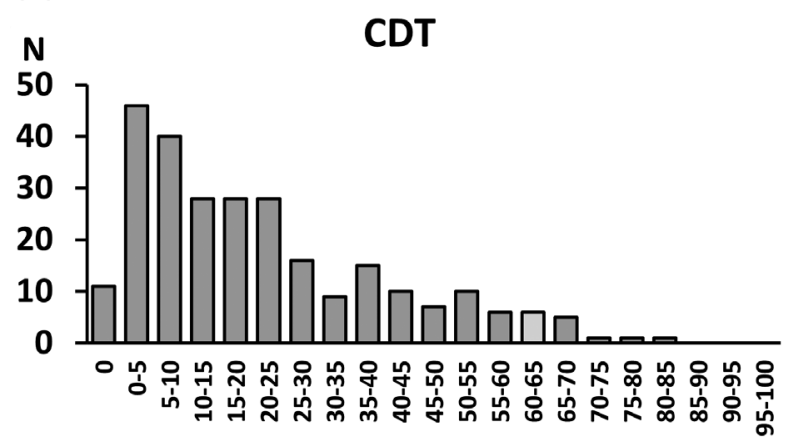

(b)

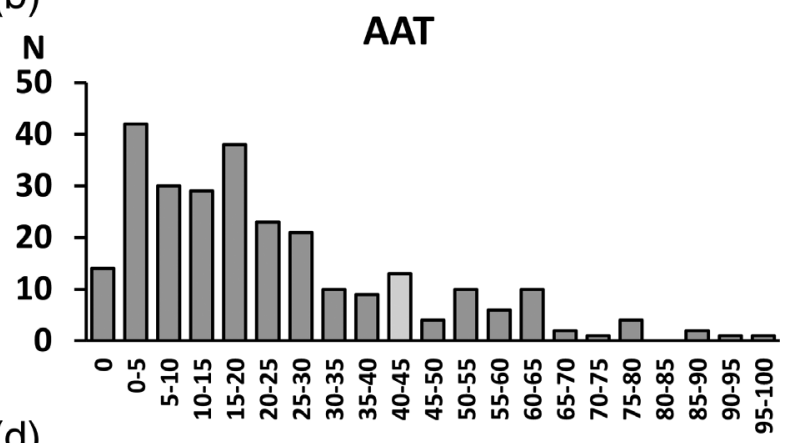

(d)

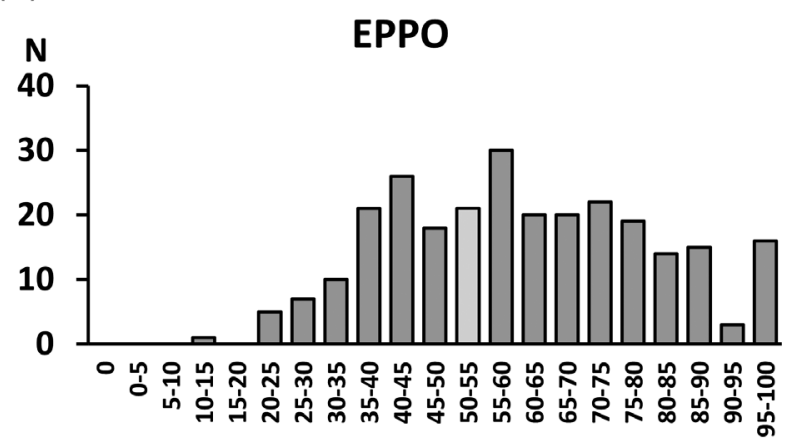

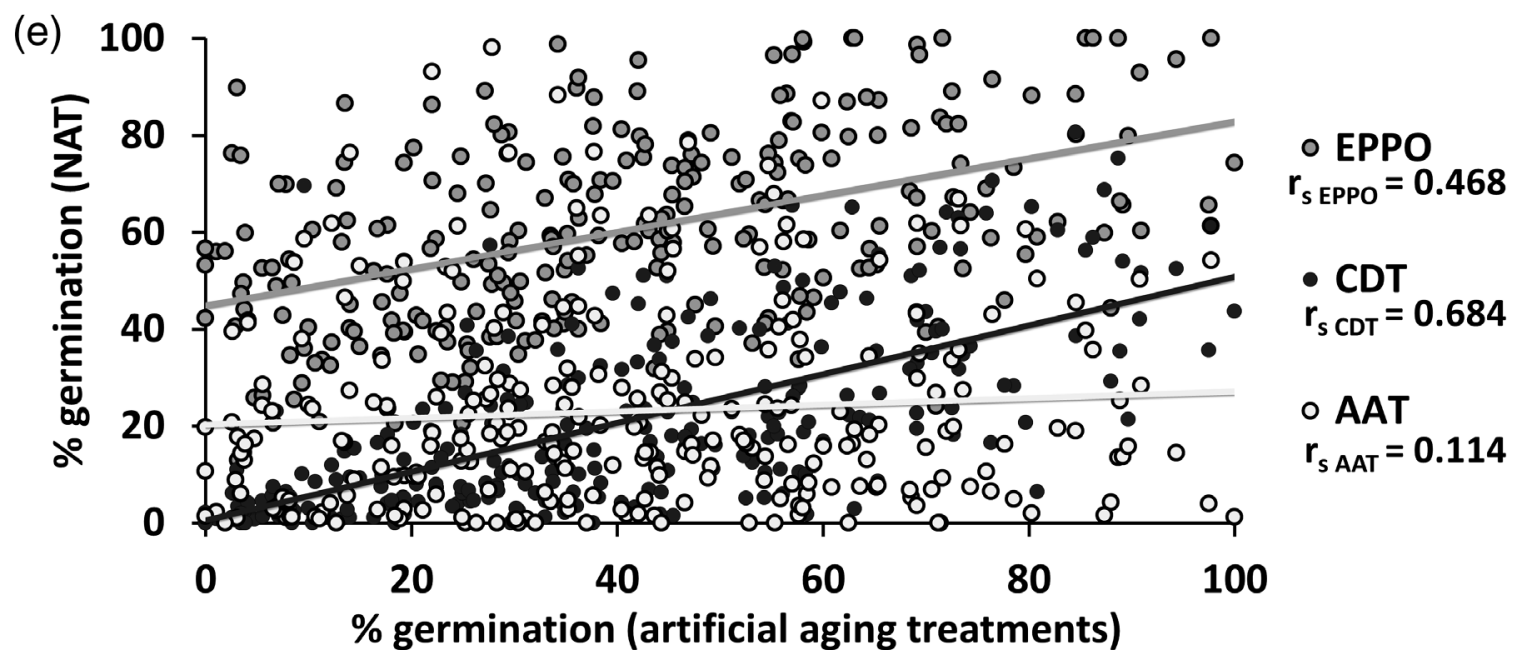

FIGURE 1 Arabidopsis ecotypes present a wide range of variability in seed deterioration resistance among all four ageing treatments. (a): Histogram distribution of 270 ecotypes after NAT. (b): AAT histogram. (c): CDT histogram. (d): EPPO histogram. Germination data of each treatment are corrected by control germination of each ecotype. Histograms represent the number of ecotypes ( $y$-axis) in the indicated range of germination ( $x$-axis). The bar in light grey corresponds to the range including the reference accession Col-0. (e): CDT correlates better to NAT. Dispersion plots of EPPO, CDT and AAT ( $y$-axis) and NAT ( $x$-axis). Regression lines are plotted and Spearman correlations are indicated for each artificial ageing correlation with NAT

TAB LE 1 Correlation indexes of different phenotypic traits with seed longevity determined with different ageing treatments (NAT, AAT, CDT and EPPO)

\begin{tabular}{|c|c|c|c|c|c|c|}
\hline & NAT & AAT & CDT & EPPO & Ecotypes & Reference \\
\hline Plant life spam & -0.35 & -0.33 & -0.30 & -0.22 & 270 & Data S3 \\
\hline Days to flower & -0.28 & -0.35 & -0.29 & -0.31 & 71 & Grimm et al. (2017) \\
\hline Fe content in leaves & -0.32 & 0.14 & -0.44 & -0.30 & 51 & Atwell et al. (2010) \\
\hline Latitude at collection point & -0.11 & 0.00 & 0.03 & 0.10 & 256 & Horton et al. (2012) \\
\hline Anthocyanin content & 0.13 & -0.01 & -0.07 & -0.09 & 83 & Atwell et al. (2010) \\
\hline
\end{tabular}

Note: Indicated correlation indexes correspond to Spearman correlations. Ecotypes column refers to the number of coinciding ecotypes in the correlations. Complete correlation information is listed in the Data S3. Upper part: correlated traits. Down part: non-correlated traits. 
(a) NAT-GWAS

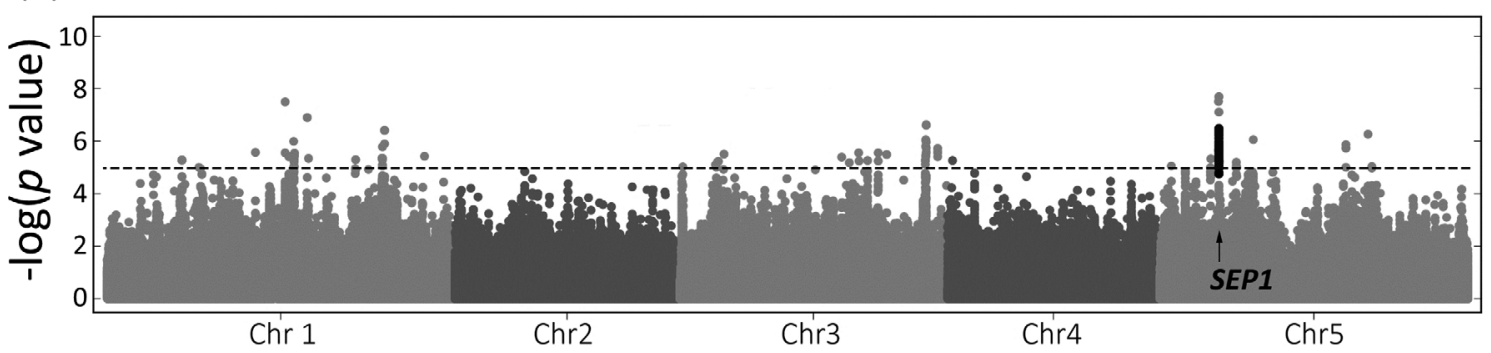

(b) AAT-GWAS

Chromosome

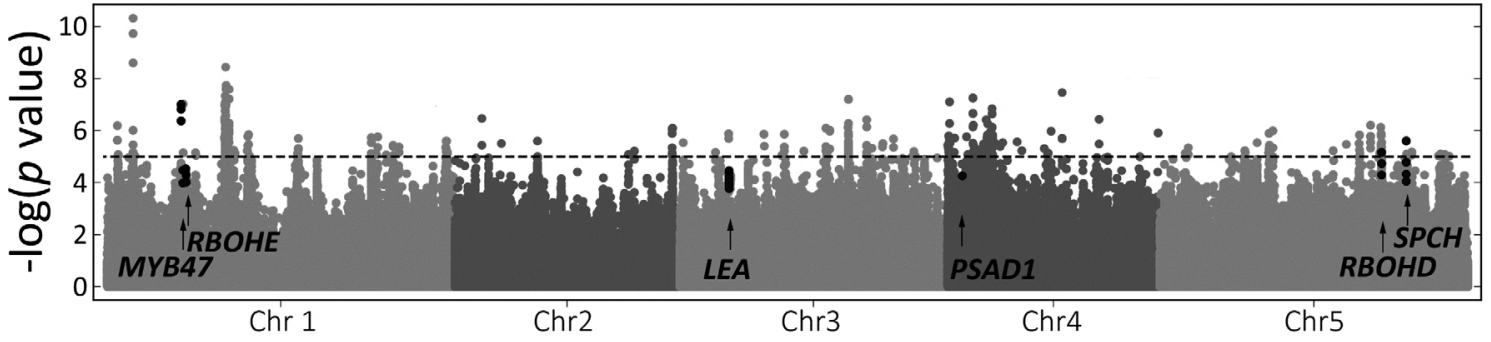

Chromosome

(c) CDT-GWAS

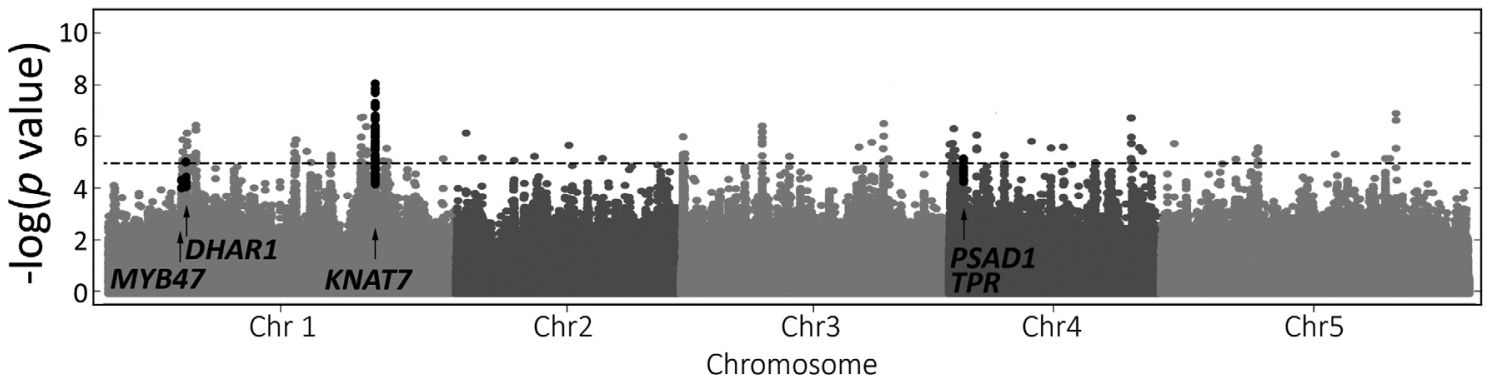

(d) EPPO-GWAS

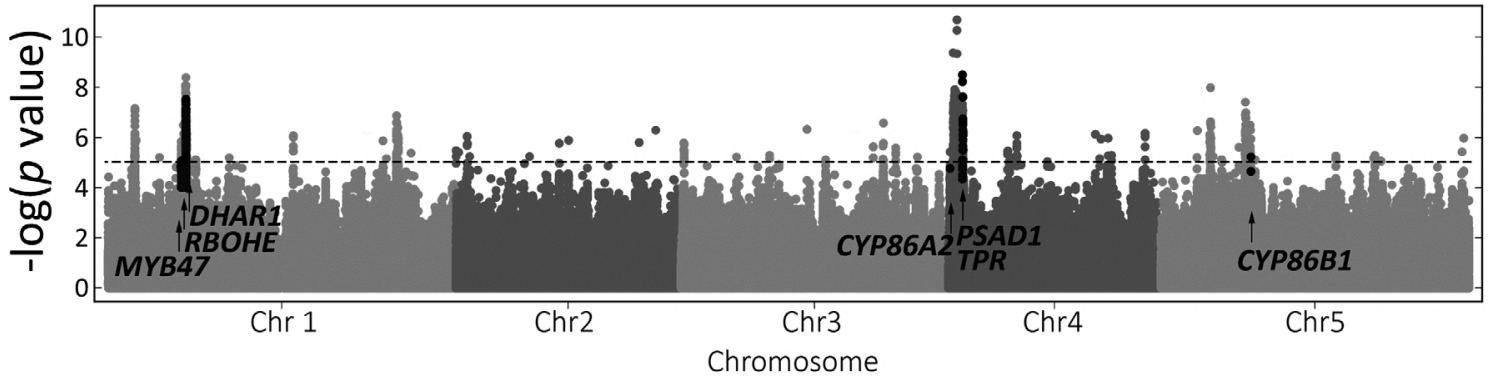

FIGURE 2 Different seed longevity GWAS highlights different and similar genomic areas. (a): NAT-GWAS Manhattan plot. (b): AAT-GWAS Manhattan plot. (c): CDT-GWAS Manhattan plot. (d): EPPO-GWAS Manhattan plot. Dashed lines indicate the threshold significance ( $p$ value $<10^{-5}$ ). In black, SNPs showing $p$ value $<10^{-4}$ that are less than $1.5 \mathrm{~kb}$ distance of genes used for reverse genetics. Arrows associate gene alias with SNPs

\subsection{ROS accumulation by NADPH oxidases (RBOHs) is detrimental for seed longevity}

Interestingly, two RBOHs genes, RBOHD (AT5G47910) and RBOHE (AT1G19230), were highlighted after AAT and EPPO treatments, respectively. $\mathrm{RBOH}$ s are transmembrane $\mathrm{NADPH}$ oxidases important for ROS production. They produce superoxide anion $\left(\mathrm{O}_{2}^{-}\right)$, rapidly transformed to $\mathrm{H}_{2} \mathrm{O}_{2}$, and play important roles in biotic and abiotic stresses (Chang et al., 2016; Qu, Yan, \& Zhang, 2017). We decided to study them, given the importance of ROS in seed ageing (Bailly, 2004; Sano et al., 2016). There are $10 \mathrm{RBOH}$ genes in Arabidopsis, named from A to J. Only three of them are abundantly expressed during seed development according to Le et al. (2010): RBOHE and RBOHF, mainly in the seed coat, and ROBHD, in the endosperm (Figure S1). Seeds of 
TAB LE 2 Highlighted genes used for reverse genetics analysis

\begin{tabular}{llll}
\hline GWAS & Score & AGI & Gene alias \\
\hline EPPO, CDT & 8.51 & AT4G02750 & SSTPR \\
\hline EPPO, AAT, CDT & 8.24 & AT4G02770 & PSAD1 \\
\hline CDT & 8.14 & AT1G62990 & KNAT7 \\
EPPO, CDT & 7.49 & AT1G19570 & DHAR1 \\
\hline AAT, EPPO, CDT & 6.99 & AT1G18710 & MYB47 \\
NAT & 6.26 & AT5G15800 & SEP1 \\
\hline AAT & 5.63 & AT5G53210 & SPCH \\
\hline EPPO & 5.54 & AT5G23190 & CYP86B1 \\
\hline AAT & 5.28 & AT5G47910 & RBOHD \\
\hline EPPO, AAT & 4.85 & AT1G19230 & RBOHE \\
\hline EPPO & 4.75 & AT4G00360 & CYP86A2 \\
\hline AAT & 4.41 & AT3G17520 & SSLEA \\
\hline
\end{tabular}

Note: GWAS column: ageing treatments where the indicated genes appeared at less than $1.5 \mathrm{~kb}$ distance of SNPs with $p$ value $\leq 10^{-4}$; Score column or $-\log (p$ value): score of most significant SNP close to the indicated gene in first-listed GWAS; AGI column: Arabidopsis gene identifier; Gene alias: gene name used in this paper. Lower part of the table corresponds to genes whose SNPs were not significant in GWAS (score between 4 and 5), but were used for reverse genetics. Complete GWAS gene-scoring information is listed in Data S4.

rbohd, rbohe and rbohf mutant plants exhibited increased longevity and the double mutant, rbohd,f has even more seed longevity. (Figure 4). RBOH-mutant seeds showed no significant seed coat alterations (Figure S4). As indicated in Table 3, these four mutants also exhibited increased seed longevity with two artificial ageing treatments (AAT and CDT).

\section{5 | DHAR1 ROS-detoxification system is important for seed longevity}

The DHAR1 (AT1G19570) gene was highlighted after the EPPO and CDT treatments. DHARs are glutathione-dependent dehydroascorbate reductases involved in ROS detoxification. They catalyse the regeneration of ascorbate oxidized during detoxification of $\mathrm{H}_{2} \mathrm{O}_{2}$ by ascorbate peroxidase (Foyer \& Noctor, 2011; Smirnoff, 2011). Given the importance of ROS in seed longevity, we decided to study the implication of this gene. Three functional isoforms are described in Arabidopsis (Dixon, Davis, \& Edwards, 2002; Dixon \& Edwards, 2010). We tested all three single mutants and the triple mutant, dhar1,2,3, in order to clarify if there is a major player contributing to seed longevity.

After 1 year of NAT treatment, dhar1 seeds already lost part of their germination ability, while dhar2 and dhar3 mutant seeds did not. The triple mutant, dhar1,2,3, exhibited the same seed longevity reduction as the single dhar1 mutant, indicating that other isoforms are not needed for seed longevity (Figure 5). According to Le et al. (2010) dataset, DHAR1 is the most abundantly expressed DHAR isoform during seed development and in mature seed (Figure S1). This expression pattern is consistent with our natural ageing results. As indicated in
TAB LE 3 Schematic results of ageing treatments (NAT, AAT and CDT) of loss-of-function mutants in Col-0 background.

\begin{tabular}{|c|c|c|c|}
\hline Mutant line & NAT & AAT & CDT \\
\hline psad1 & Susceptible** & Susceptible* & Susceptible** \\
\hline sslea & Susceptible** & Susceptible* & Susceptible* \\
\hline sstpr & Susceptible** & Susceptible* & Susceptible* \\
\hline rbohd & Resistant* & Resistant* & Resistant* \\
\hline rbohe & Resistant* & Resistant* & Resistant** \\
\hline rbohf & Resistant* & Resistant* & Resistant* \\
\hline rbohd,f & Resistant** & n.s. & Resistant** \\
\hline dhar1 & Susceptible** & Susceptible* & Susceptible** \\
\hline dhar2 & n.s. & n.s. & n.s. \\
\hline dhar3 & n.s. & n.s. & Susceptible** \\
\hline dhar1,2,3 & Susceptible* & Susceptible* & Susceptible* \\
\hline сур86а1 & n.s. & n.s. & n.s. \\
\hline сур86а2 & n.s. & n.s. & n.s. \\
\hline сур86а8 & Susceptible** & Susceptible** & Susceptible* \\
\hline cyp86b1 & n.s. & n.s. & n.s. \\
\hline cyp86b2 & n.s. & n.s. & n.s. \\
\hline сур86с1 & n.s. & Susceptible* & n.s. \\
\hline myb47 & Susceptible** & Susceptible* & Susceptible* \\
\hline spch & Susceptible** & Susceptible* & Susceptible* \\
\hline knat7 & Resistant** & Resistant* & Resistant* \\
\hline sep3 & Resistant** & Resistant** & Resistant** \\
\hline $\operatorname{sep} 1,2,4$ & n.s. & Resistant** & n.s. \\
\hline
\end{tabular}

Note: Reduced seed germination (Susceptible), increased seed germination (Resistant) or non-significant changes in germination after the ageing treatment (n.s.) in comparison to $\mathrm{Col}-0$ seeds. ${ }^{*}$ Significantly differing from wild-type seeds at $p<.05$ (Student's $t$ test). ${ }^{* *}$ Significantly differing from wild-type seeds at $p<.01$ (Student's $t$ test). Supporting numerical and statistical data are given in Data S5.

Table 3, dhar1 and dhar1,2,3 mutants also exhibited reduced seed longevity with both artificial ageing treatments (AAT and CDT).

\section{6 | CYP86A8 is involved in synthesis of seed lipid-polyesters needed for seed longevity}

GWAS highlights genomic areas, causing the observed natural variation of traits (Curtin et al., 2017). Natural variation, however, may affect less to major player genes due to their important physiological role. Here, we present the example of a gene family, whose two members were highlighted after the ageing treatments, although a third member resulted to be more important for seed longevity in a mutant background. After the EPPO treatment, CYP86A2 (AT4G00360) and CYP86B1 (AT5G23190) were highlighted. They are related to suberin and cutin biosynthesis (Bak et al., 2011), lipid polymers involved in seed permeability and recent results suggest an important role in seed longevity (Renard et al., 2020). 


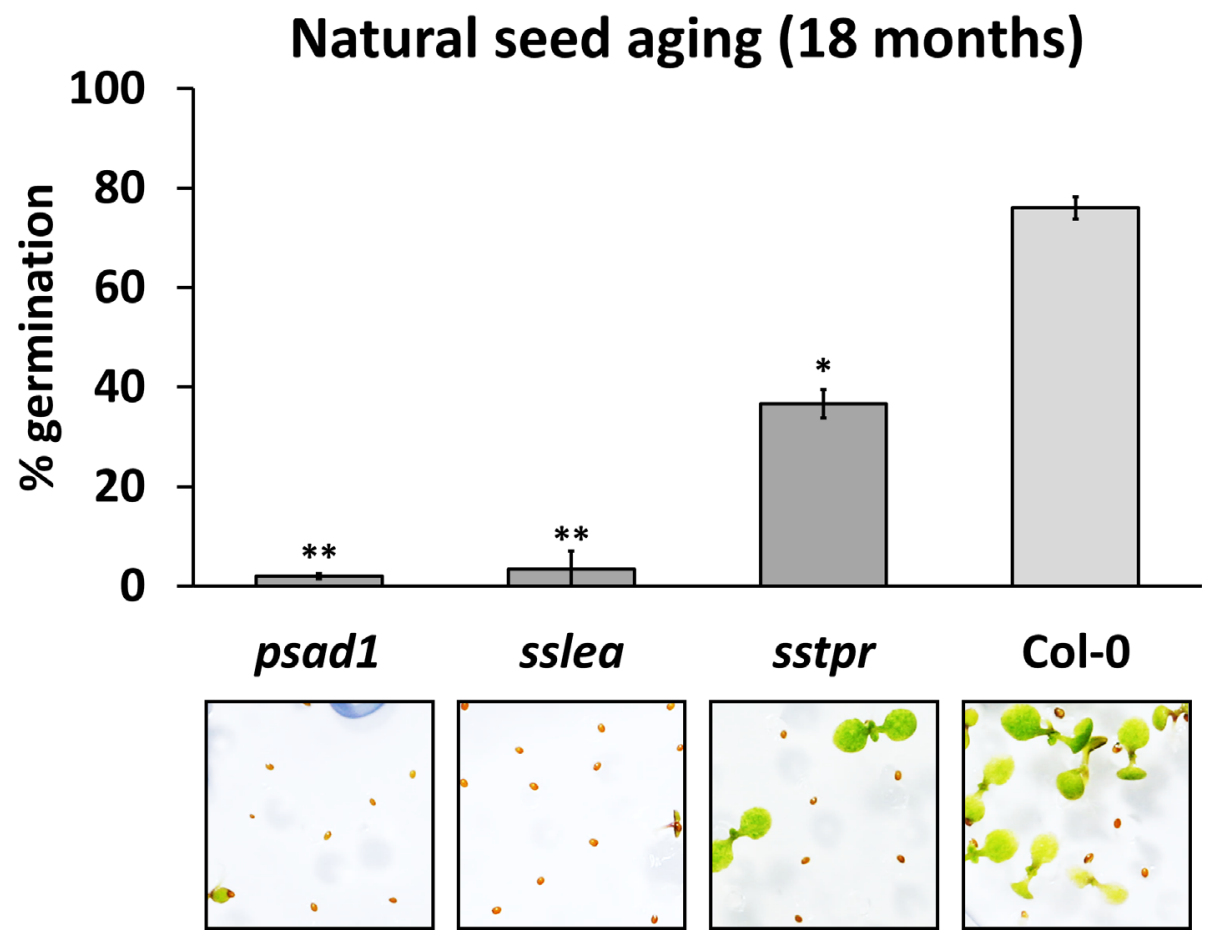

FIGURE 3 Seeds of psad1, sslea and sstrp mutants exhibit reduced seed longevity. Seed lots were stored for 18 months under natural conditions (see Materials and Methods) and sown on MS plates. Above: The percentage of germination was recorded after 1 week. The results are the average of three experiments with 50 seeds per line. Bars indicate standard errors. Not-aged seeds from all lines germinated more than 95\%. *Significantly differing from wild-type seeds at $p<.05$ (Student's $t$ test). ** Significantly differing from wild-type seeds at $p<.01$ (Student's $t$ test). Below: representative images

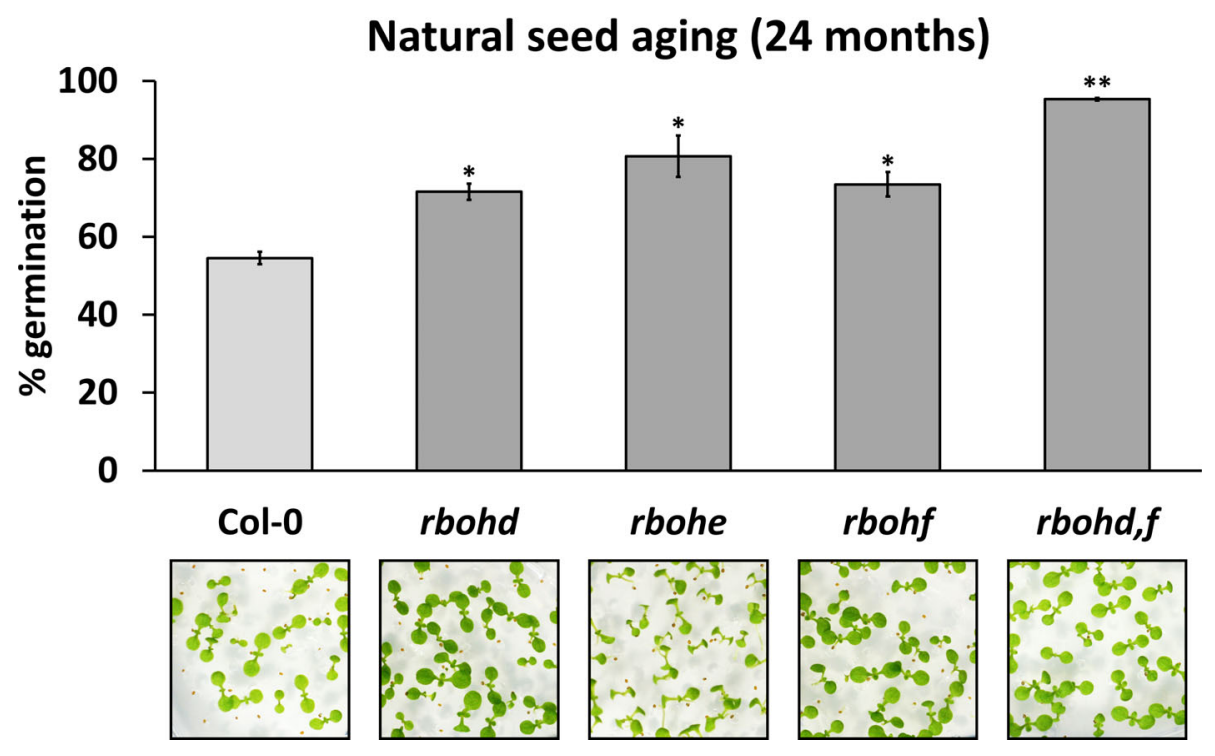

FIGURE 4 Seeds of rbohd, rbohe, rbohf and double mutant rbohd,f exhibit increased seed longevity. Seed lots were stored for 24 months and sown on MS plates. Above: The percentage of germination was recorded after 1 week. The results are the average of three experiments with 50 seeds per line. Bars indicate standard errors. Not-aged seeds from all lines germinated more than $97 \%$. *Significantly differing from wild-type seeds at $p<.05$ (Student's $t$ test).

${ }^{* *}$ Significantly differing from wild-type seeds at $p<.01$ (Student's $t$ test). Below: representative images

We obtained T-DNA mutant lines affecting the members of the CYP86 family abundantly expressed in seeds accordingly to Le et al. (2010) data (Figure S2): CYP86A1 (AT5G58860), CYP86A2 (AT4G00360), CYP86A8 (AT2G45970), CYP86B1 (AT5G23190), CYP86B2 (AT5G08250) and CYP86C1 (AT1G24540). A T-DNA insertion line close to CYP86C3 was not available. After 1 year of seed dry storage, only seeds of cyp86a8 showed a drastic reduction in their germination (Figure 6a), which is also observed during AAT and CDT treatments (Table 3). Interestingly, cyp86a8 seeds are notably different to wild type: they are rounder, they present a reduced lipid polyester staining (Figure 6b) and they are more permeable due to the higher rate of tetrazolium reduction (Figure 6c).

\section{7 | TFs expressed in seed coat and endosperm are important for seed longevity}

Transcription factors (TFs) are essential for seed coat differentiation. We found some transcription factors expressed in seed coat and endosperm (Le et al., 2010) among our candidate gene list. SEP1 (AT5G15800) highlighted after natural ageing, KNAT7 (AT1G62990) highlighted in the CDT treatment, SPCH (AT5G53210) highlighted in the AAT, and MYB47 (AT1G18710) highlighted in all three artificial ageing treatments.

Seeds of myb47 and spch showed an important reduction of seed longevity, while seed longevity of knat7 and sep3 (but not of sep1,2,4) 
FIGURE 5 Seeds of dhar1 and triple mutant dhar1,2,3 present a reduced seed longevity, but dhar2 and dhar3 seeds no phenotype. Seed lots were stored for 12 months and sown on MS plates. Above: The percentage of germination was recorded after 1 week. The results are the average of three experiments with 50 seeds per line. Bars indicate standard errors. Not-aged seeds from all lines germinated more than $99 \%$. *Significantly differing from wild-type seeds at $p<.05$ (Student's $t$ test). Below: representative images

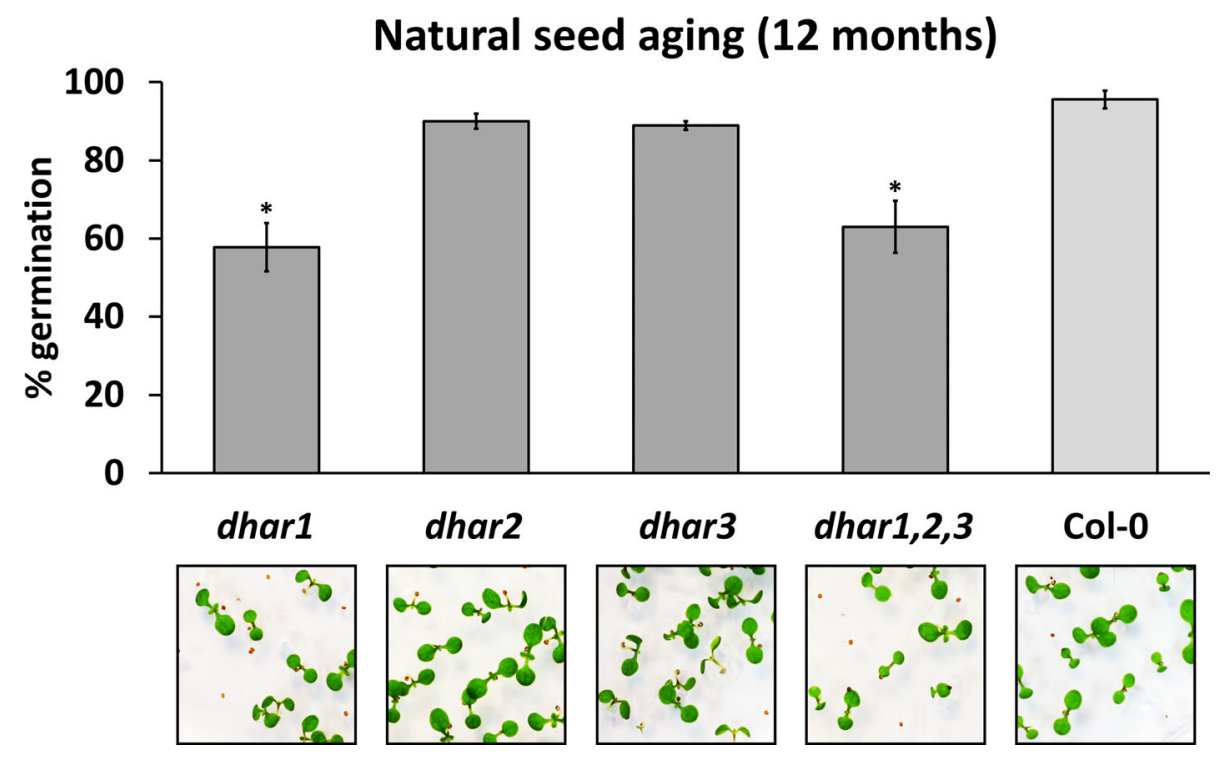

(a) Natural seed aging (12 months)

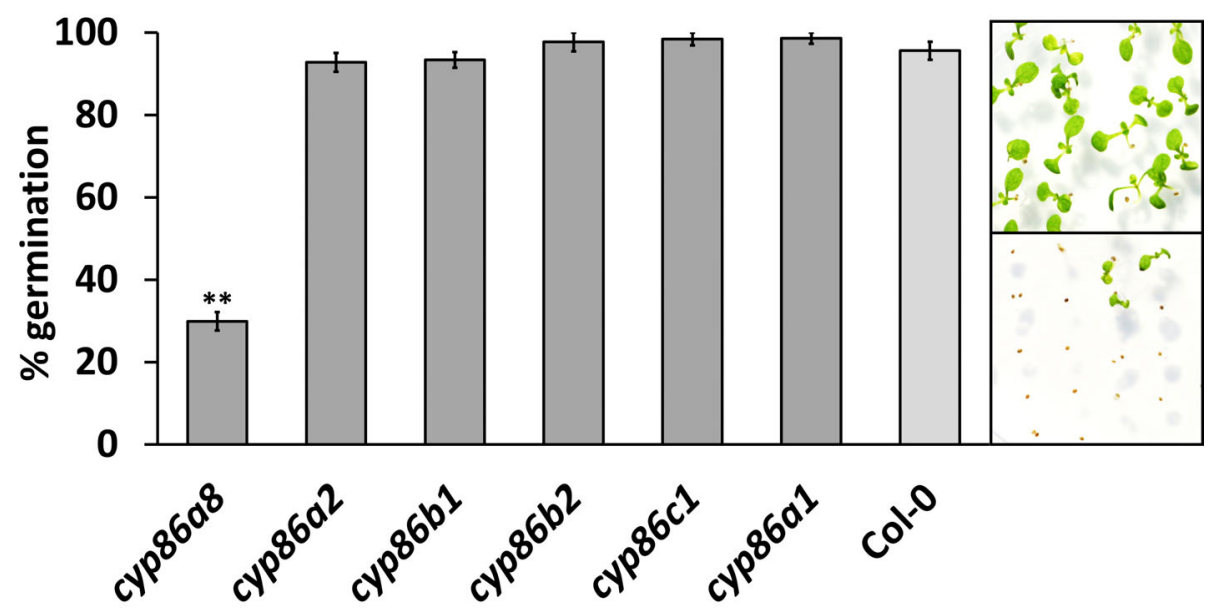

(b)

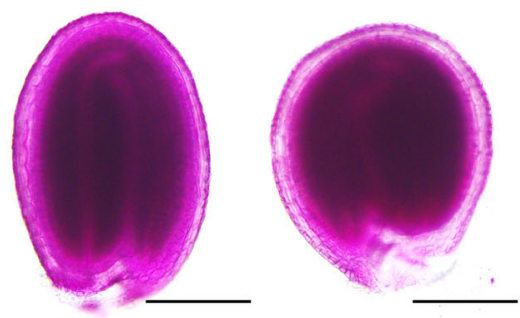

(c)

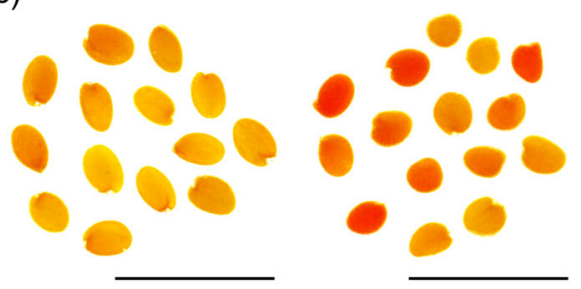

FIGURE 6 Reduced seed longevity of mutant cyp86a8 correlates with reduced lipid polyester barriers. (a): Seeds of cyp86a8 present a drastically reduced seed longevity, while seeds of mutant plants in other family members have no phenotype. Seed lots were stored for 12 months and sown on MS plates. Left: The percentage of germination was recorded after 1 week. Results are the average of three experiments with 50 seeds per line. Bars indicate standard errors. Not-aged seeds from all lines germinated more than $95 \% .{ }^{* *}$ Significantly differing from wild type seeds at $p<.01$ (Student's $t$ test). Right: representative images of Col-0 (up) and cyp86a8 (down) germination. (b): Mutant cyp86a8 seeds present a reduced suberin layer and a rounded shape. Representative image of Sudan red staining of Col-0 (left) and cyp86a8 (right) seeds. Scale bars: $200 \mu \mathrm{m}$. (c): Mutant seeds of cyp86a8 are more permeable than Col-0 seeds. Tetrazolium reduction assay (24 hr) in Col-0 (left) and cyp86a8 (right) seeds. Scale bars: $2 \mathrm{~mm}$

was increased (Figure 7a). Similar behaviour was observed in artificial ageing tests (Table 3). Here, a candidate gene (SEP1) was again not the member of the gene family with the strongest seed-phenotype (this was sep3). As those TFs were expressed in the seed coat (Figure S1), we performed a tetrazolium assay to assess their seed coat permeability (Figure 7b). Seeds of myb47 and sep1,2,4 do no 
(a) Natural seed aging (24 months)

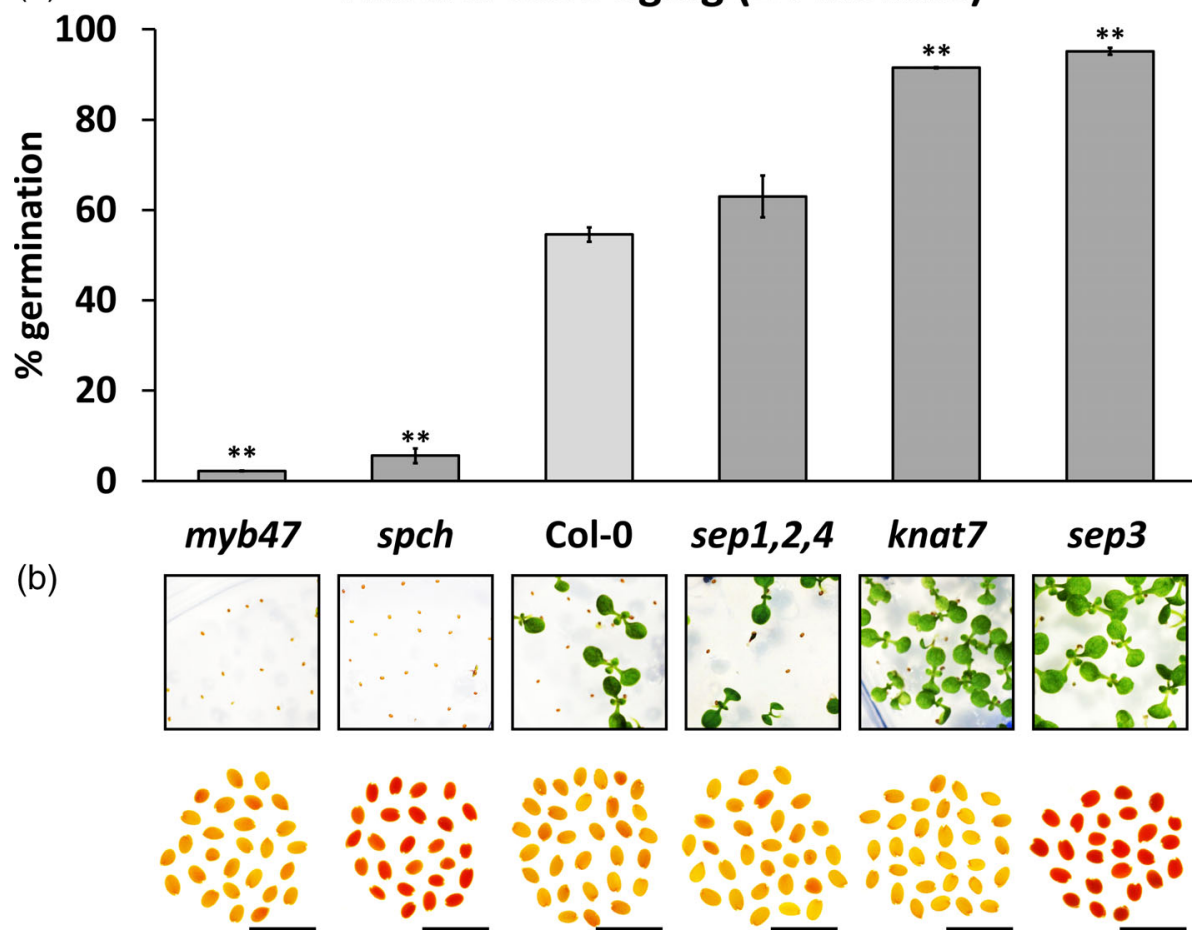

FIGURE 7 Mutants of different TFs exhibit differences in seed longevity and seed coat permeability. (a): Seeds of spch and myb47 have reduced seed longevity; seeds of knat7 and sep3 have increased seed longevity, but triple mutant sep1,2,4 has no phenotype. Seed lots were stored for 24 months and sown on MS plates. Above: The percentage of germination was recorded after 1 week. The results are the average of three experiments with 50 seeds per line. Bars indicate standard errors. Not-aged seeds from all lines germinated more than $97 \%$.

${ }^{* *}$ Significantly differing from wild-type seeds at $p<.01$ (Student's $t$ test). Below: representative images. (b): Mutant seeds of spch and sep3 are more permeable and knat7 seeds are less permeable than Col-0 seeds. Tetrazolium reduction assay (24 hr) in myb47, spch, Col-0, knat7 and sep3 seeds. Scale bars: $2 \mathrm{~mm}$ present significant differences to Col-0 seeds. Interestingly, spch and knat7 seeds present enhanced and reduced tetrazolium salt reduction, respectively, in correlation with their seed longevity phenotype (Figure S6a for knat7 seeds). Surprisingly, sep3 seeds present a high reduction to tetrazolium salts. Seed coat assays to visualize proanthocyanidins (PAs), the mucilage halo, the suberin layer and seed size were performed. Differences were observed only in sep3 and knat7 seeds. As described, knat7 mutant seeds present less mucilage extrusion (Romano et al., 2012), and sep3 seeds exhibit a similar feature (Figure S5). Seed size is reduced in knat7 seeds (Figure S6b,c) and sep 3 seeds presented a rounder shape (Figure 7b).

\section{8 | MYB47 is expressed in the seed coat and it is a positive regulator of seed longevity}

To further investigate the MYB47 mechanism, we developed Arabidopsis transgenic lines. Confocal imaging of proMYB47::GFP plants locates the expression of MYB47 in the seed coat during seed development. More precisely, GFP expression was visualized during first days of seed development in the seed coat, and in latter days, it was localized at the chalaza (Figure 8a). This expression pattern fits with Le et al. (2010) data (Figure S1).

Overexpression of MYB47, driven by the UBQ10 promotor, conferred resistance to AAT and CDT treatments compared to wild-type plants in three independent lines, highlighting the importance of MYB47 in seed longevity as a positive regulator (Figure 8b). Expression analysis in seedlings demonstrates differences in MYB47 gene expression among different overexpressing lines. The myb47 mutant has 30-fold reduction of MYB47 gene expression, while over- expression lines overexpressed MYB47 around 35- and 60-fold compared to wild-type plants (Figure 8c). Although MYB47 expression is located in seed coat during seed development, we did not observe significant differences in seed coat component abundance (mucilage, PAs, or lipid polyester barriers) among overexpressing lines, compared to Col-0 (Figure S7).

\section{4 | DISCUSSION}

Many of the genes required for seed longevity are still unknown. In this work, we have utilized a combination of GWAS, rational filtering and reverse genetics in Arabidopsis thaliana Col-0 to identify 12 novel genes involved in this trait. Seven are positive for longevity (PSAD1, SSLEA, SSTPR, DHAR1, CYP86A8, MYB47 and SPCH) as their knockout mutants have less seed longevity than their corresponding wild type. Five are negative ones (RBOHD, RBOHE, RBOHF, KNAT7 and $S E P 3)$ as their knock-out mutants have more seed longevity than their corresponding wild type. These results contribute to the understanding of this polygenic trait.

Our data demonstrate a wide variation in seed longevity among Arabidopsis ecotypes. Correlations between artificial and natural ageing treatments indicate that, with exception of the AAT case, CDT and EPPO are valuable treatments to test seed longevity (Figure 1). Bueso et al. (2014) reported a good correlation between AAT and NAT. However, their plant material consisted of mutant lines in the same Arabidopsis background. In our case, each ecotype presents a different background genome, affecting the expression of multiple genetic components, probably causing this miss-correlation. In our TDNA mutant approach, lines have the same genetic background (Col- 
(a)
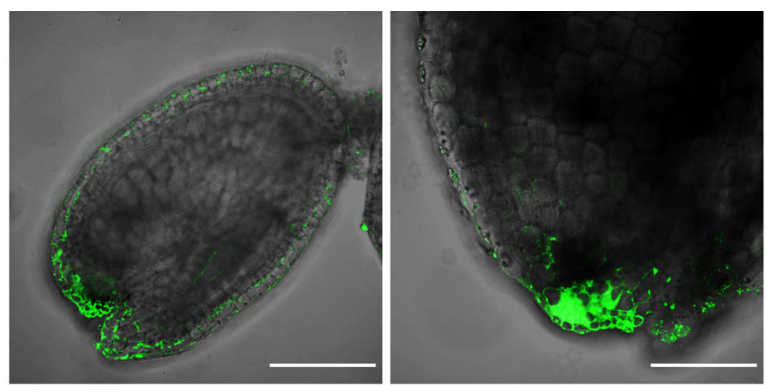

(b)
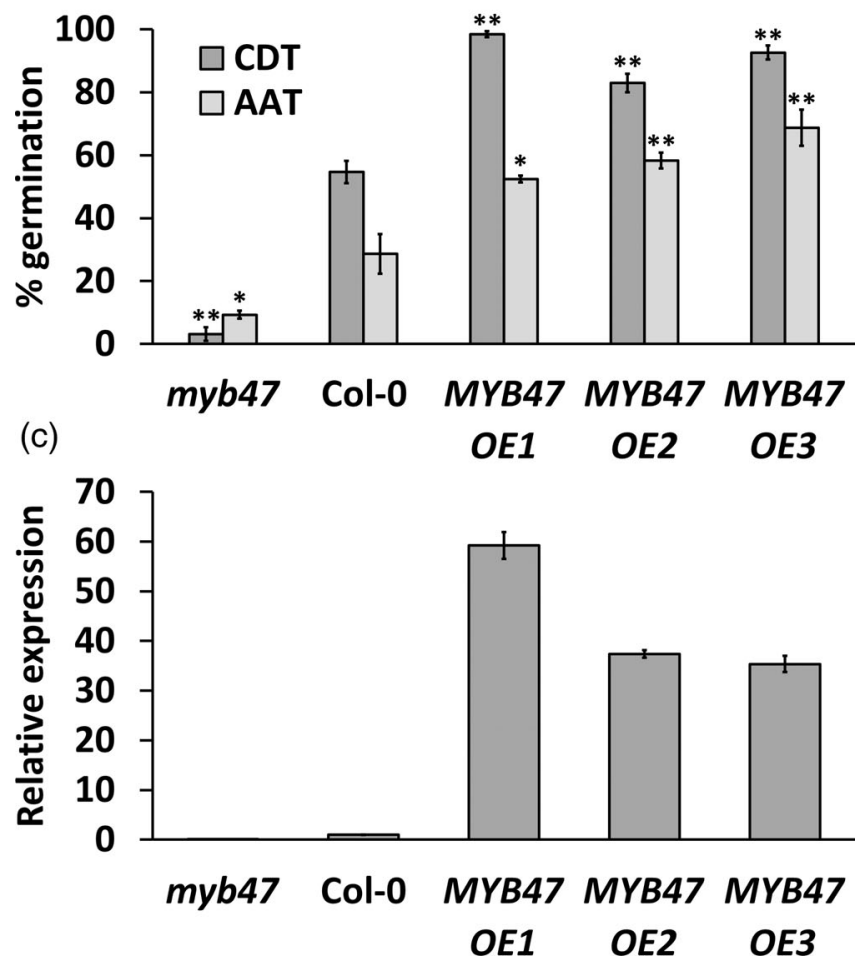

FIGURE 8 MYB47 is a positive TF gene for seed longevity and it is expressed in the chalaza during seed development. (a): MYB47 expression during seed development is localized initially at the seed coat (left, DAP3) and later in the chalaza (right, DAP7). Confocal imaging of developing seeds of proMYB47::GFP plants. Scale bar: $100 \mu \mathrm{m}$. (b): Seeds of three independent lines over-expressing MYB47 are more resistant to accelerated ageing treatments, CDT (dark bars) and AAT (light bars). The percentage of germination was recorded after 1 week. The results are the average of three experiments with 50 seeds per line. Bars indicate standard errors. Not-aged seeds from all lines germinated more than $99 \%$. ${ }^{*}$ Significant differences from wild-type seeds at $p<.05$ (Student's $t$ test). ${ }^{* *}$ Significantly differing from wild-type seeds at $p<.01$ (Student's $t$ test). (c): qRT-PCR gene expression analysis of MYB47 in 7 days old seedlings from myb47 mutant and three MYB47 over-expressing lines. Expression values are relative to housekeeping gene, PP2AA3, and the resulting ratios are normalized to wild type, taken as 1 . Results are the average of three determinations with bars corresponding to standard errors

0 ) and behave similarly with natural AAT and CDT ageing procedures (Table 3), as in Bueso et al. (2014) experiments.

One important aspect observed in natural variation of seed longevity is that it inversely correlates with plant life span, flowering time and rossette leaf number (Table 1). These phenotypes are linked, as rosette leaf number increases as flowering delays, and plant life spam is dependent on flowering time to ensure plant reproduction. Flowering initiates the developmental program of tissues that will develop into seeds. In some way, the rapid flowering initiation signals must be important for seed development and seed longevity acquisition, although the connection is not straightforward. There are no previous reports concerning this trait association. No correlation with ecotype latitude-collection point discards an effect of temperature or photoperiod on adaptation of seed-longevity. The negative correlation found between seed longevity and iron content has been already suggested (Murgia et al., 2015). It is plausible that high amounts of iron drives oxidative stress during seed storage. Seed dormancy, described to be inversely correlated with seed longevity (Nguyen, Keizer, van Eeuwijk, Smeekens, \& Bentsink, 2012), did not correlated with our longevity data. Anthocyanin content influences PAs deposition in seed coats, a component putatively implicated in seed longevity (Debeaujon et al., 2000) but was not correlated.

\subsection{New mechanisms regulating seed longevity}

The AAT treatment highlighted an LEA protein (AT3G17520) that we named as SSLEA after the observed reduced seed storability of the mutant. There are 71 putative LEA proteins in Arabidopsis and their functions are usually associated with desiccation tolerance. A link between seed longevity and LEA proteins has been proposed based on the RNA interference targeting of LEA14 of Arabidopsis, resulting in decreased seed longevity (Hundertmarkt et al., 2011). This LEA protein belongs to group 2 (dehydrins) and SSLEA belongs to group 6 according to Jaspard, Macherel, and Hunault (2012). Dry seeds of the sslea mutant are able to germinate completely after ripening, but germination ability decays rapidly in months. This fact discards that sslea mutant seeds cannot cope with desiccation.

The EPPO treatment highlighted a tetratricopeptide-repeat (TPR) protein (AT4G02750) that we named as SSTPR after the reduced seed storability of the mutant. These mutant seeds exhibit a high permeability by the tetrazolium test. SSTPR belongs to the TPR-PTR (tetratricopeptide-pentatricopeptide) family of repeat domain proteins (Sharma \& Pandey, 2016). Not much is known about this TPR protein or other family members. PTRs are described to play constitutive and essential roles in mitochondria and chloroplasts, probably binding to RNA (Lurin et al., 2004). Indeed, SSTPR protein is sub-localized in the mitochondria according to Hooper et al. (2017).

\section{2 | ROS generation and detoxification are important in seed longevity}

All three artificial ageing treatments highlighted genes involved in the ROS metabolism and detoxification. It has been widely accepted that this oxidative damage is one of the major causes of seed ageing. This ROS negative effect has been remarked by the ROS-producing 
enzymes, RBOHD, RBOHE and RBHOF, the ROS detoxification system, involving DHAR1, and the photosystem I subunit, PSAD1. ROS signalling is essential for diverse cellular processes and developmental programs. It is involved in the fine-tuning of the hypersensitive response (HR) upon pathogen infection, abiotic stress signalling and in hormone and developmental signalling, including programmed cell death (PCD) (Marino, Dunand, Puppo, \& Pauly, 2012; Miller, Shulaev, \& Mittler, 2008; Suzuki et al., 2011). In seeds, ROS are required for embryogenesis, programmed cell death of the seed coat and endosperm, as well as during seed germination, and act as protection against pathogens (Bailly, El-Maarouf-Bouteau, \& Corbineau, 2008; Jeevan Kumar, Rajendra Prasad, Banerjee, \& Thammineni, 2015; Murphy, Asard, \& Cross, 1998). Here, we present evidence that RBOH-produced $\mathrm{ROS}$ are a major cause of deterioration during ageing. The enhanced seed longevity of $\mathrm{RBOH}$ mutants could indicate $\mathrm{RBOH}-\mathrm{ROS}$ activity through seed storage. RBOHE and RBOHF are expressed in the seed coat and RBOHD in the endosperm and embryo (Figure S1), pointing to a role during cell death of these tissues. Plants express these proteins in mature seeds because ROS are needed for maturation of the seed coat and for defence against pathogen attack (Jeevan Kumar et al., 2015).

A ROS-detoxification system has been highlighted by means of the DHAR1 gene. DHARs are glutathione-dependent dehydroascorbate reductases. They catalyse the regeneration of ascorbate oxidized during detoxification of $\mathrm{H}_{2} \mathrm{O}_{2}$ by ascorbate peroxidase (Foyer \& Noctor, 2011; Smirnoff, 2011). This model is supported by the high oxidation of glutathione in the triple mutant, dhar1,2,3 (Rahantaniaina et al., 2017) and the use of glutathione redox equilibrium as a seed viability marker (Kranner, Birtić, Anderson, \& Pritchard, 2006). Over-expression of ascorbate peroxidases leads to resistance to oxidative stress (Wang, Zhang, \& Allen, 1999), highlighting the importance of this ROSdetoxification system. We observed that plants lacking DHAR1, but not $D H A R 2$ or DHAR3, presented less seed longevity, probably because less ROS detoxification. This is consistent with their expression profiles, with DHAR1 being the most expressed isoform in the seed embryo (Le et al., 2010).

Another highlighted ROS-related protein is the Photosystem I subunit D1 or PSAD1 (AT4G02770). It participates in the stability of this photosystem (Ihnatowicz et al., 2004). This hydrophilic protein is exposed in the stroma and interacts directly with ferredoxin in the electron transport chain (Andersen, Koch, \& Scheller, 1992; Merati \& Zanetti, 1987; Zilber \& Malkin, 1988). Although there is a homologue gene in Arabidopsis (PSAD2), PASD1 loss of function leads to growth defect due to a deficient photosynthesis, indicating that PSAD2 is not completely redundant to PSAD1. Mutant psad1 plants are pale-green and dwarf, and they have an increased photosensitivity and altered redox state of the stroma (Haldrup, Lunde, \& Scheller, 2003). The double mutant, psad1 psad2, is not viable (Ihnatowicz et al., 2004). The importance of PSAD1 in seed longevity points to its role in photosynthesis and the imbalance of photosystems in the mutant plant. An imbalance of photosystems leads to increased ROS production (Pinnola \& Bassi, 2018) and this may explain the reduced seed longevity phenotype. PSAD1 transcripts are highly expressed at the embryo in latter stages of seed development according to Le et al. (2010) data (Figure S1). Chlorophyll develops during embryo development for proper seed filling (Goffman, Alonso, Schwender, Shachar-Hill, \& Ohlrogge, 2005; Ruuska, Girke, Benning, \& Ohlrogge, 2002) and the latter disappears for seed storage, avoiding light-induced ROS accumulation (Nakajima, Ito, Tanaka, \& Tanaka, 2012). However, we cannot discard that no direct correlation may exist and that the seed longevity phenotype of psad1 seeds is due to seed developmental problems, which are due to the strong pale and dwarf phenotype observed in the mutant plant.

\section{3 | Lipid polyester barriers prevent embryo ageing}

The physical protection by seed coat, through lipids polyester barriers, has been highlighted in our study by two members of the CYP86 family. The CYP86 family belongs to the cytochrome P450 superfamily, with 244 members in Arabidopsis and is involved in numerous metabolic pathways in all organisms (Mansuy, 1998; Nelson, 1999). Members of the CYP86 gene family catalyse the $\omega$-hydroxylation of fatty acids (Benveniste et al., 1998; Duan \& Schuler, 2005; Wellesen et al., 2001), and mutant plants in different CYP86 members show a reduction in $\omega$-hydroxy fatty acids and $\alpha, \omega$-dicarboxylic fatty acids (Compagnon et al., 2009; Höfer et al., 2008; Kai et al., 2009). CYP86 enzymes participate in the synthesis of lipid-polyester barriers, such as cutin and suberin (Watson et al., 2001; Compagnon et al., 2009; Kannangara et al., 2007). Recent studies point to an important role of these lipid polyester barriers in seed longevity and tetrazolium impermeability (Beisson et al., 2007; Bueso et al., 2016; Renard et al., 2020; Yadav et al., 2014).

The drastic reduction of seed longevity, the high tetrazolium reduction rate and the lighter Sudan red staining suggest that cyp86a8 seeds are more permeable due to a reduced suberin and/or cutin layer. With this analysis, we can conclude that CYP86A8 is probably the major cytochrome, P-450, of the CYP86 family, producing the $\omega$-hydroxylation for seed lipid-polyester synthesis, necessary for seed longevity. However, CYP86A8 is also important for diverse developmental and signalling processes as described by Wellesen et al. (2001), and we cannot discard that these processes are affecting also seed development.

\subsection{TFs modulate seed longevity in different ways}

The first physical barrier to protect the seed embryo is the seed coat, which requires a precise developmental program of its cell layers. Floral identity TFs regulate the ovule integuments that will develop into the seed coat. Many TFs and different protein-protein interactions, important for seed coat development, have been described (Sano et al., 2016; Golz et al., 2018). However, the complete TF cascade is far to be completely known. Here, we demonstrate the implication of 
four TFs in the seed development transcriptional programme, whose mutant lines present seeds with altered seed longevity: SEP3, SPCH, KNAT7 and MYB47.

SEP3 is part of the SEPALLATA (SEP) gene family, formed by four MAD-box TFs (Pelaz et al., 2000). They interact with other MAD-box proteins to determine flowering and ovule development (Favaro et al., 2003; Hugouvieux et al., 2018). They are not completely redundant as they differ in DNA-binding patterns (Jetha, Theißen, \& Melzer, 2014; Soza, Snelson, Hewett Hazelton, \& Di Stilio, 2016). SEP1 was highlighted in our analysis, but we found SEP3 to be determinant, due to the enhanced seed longevity and seed coat phenotype of sep 3 mutant seeds. The different seed shape and the reduced mucilage halo of sep3 seeds suggest that SEP3 has a role in seed coat development. The SEP3 seed-coat expression pattern, during seed development (Le et al., 2010), supports this idea. The results of the tetrazolium reduction by sep3 seeds are intriguing. Normally, tetrazolium salts reduction is related with a higher seed coat permeability, which is inversely correlated to seed longevity (Debeaujon et al., 2000). Mutant seeds of two SEP3 interactors present similar trait effects: stk seeds present a round shape as sep3 seeds do (Mizzotti et al., 2014) and tt16 seeds present high tetrazolium reduction rate (Debeaujon et al., 2000). Both of them are involved in inner integument regulation and seed shape (Coen et al., 2017). An explanation could be that sep3 seed coat is physically different, perhaps softer. Internal embryo pressure would be responsible for this round shape. Pressure may be stronger during seed development and during water imbibition (producing seed coat fissures), but not significant in the dry stage. This would explain the miss-correlation between tetrazolium reduction and their enhanced seed longevity in the dry state.

$\mathrm{SPCH}$ is a well-described basic helix-loop-helix (bHLH) TF involved in stomatal lineage determination during the asymmetrical division of future guard cells (MacAlister et al., 2007). Mutant plants have no stomata at all. They have been widely studied for stomata formation but not in relation with seed development and longevity. We found that seed longevity of spch mutant seeds was reduced. Tetrazolium assay in spch seeds showed enhanced permeability (Figure $7 \mathrm{~b}$ ), indicating a putative function in seed development.

KNAT7 is a homeobox-TF and seeds of the knat7 mutant are more tolerant to seed ageing, and they are notably smaller and present decreased tetrazolium reduction (Figure S6). knat7 mutant seeds have been described to have affected the epidermal cells responsible for mucilage secretion (Romano et al., 2012). The expression pattern is at seed coat during last maturation stages (Figure S1). Recent studies propose that KNAT7 inhibits cell wall formation by regulating lignin synthesis through interaction with BHL6 and MYB75 (Bhargava et al., 2013; Liu et al., 2014). Cell wall deposition is an important aspect of seed coat development and seed longevity, and the absence of this TF must improve it.

MYB47 is the only TF not previously described in other works. It belongs to R2-R3 MYB transcription factor family formed by 126 members involved in the regulation of diverse metabolic pathways, including PAs, suberin and cuticle biosynthesis (Dubos et al., 2010). MYB47 was highlighted after the three artificial treatments (AAT, CDT and EPPO) and mutant seeds present reduced seed longevity. Over-expression plants had enhanced seed longevity, confirmed with artificial ageing treatments (Figure 8b). This corroborates its positive effect in seed longevity. GFP promotor-driven expression locates MYB47 expression in the seed coat during seed development, coinciding with published expression dataset (Figure S1). Nevertheless, we did not find differences in mucilage, lipid polyester staining or PAs deposition in the knockout mutant or in the over-expression mutants (Figure S7). Thus, MYB47 participates in an important seed coat mechanism contributing to seed longevity, not related with seed coat components, such as PAs, mucilage or lipid polyester barriers, pointing to a new unknown protecting mechanism of the seed coat, which remains unclear.

We have provided insights of the participation of four TFs in the seed longevity trait. Observed seed phenotypes suggest a role of these four seed TFs in seed coat development. However, further study is necessary to complete the understanding of these TFs and their role in the TFs cascade, regulating seed development. Seed RNA-seq analysis of these mutants might provide us new players and new molecular mechanisms involved in seed longevity.

\section{5 | CONCLUDING REMARKS}

Our work demonstrates the power of combining GWAS and reverse genetics to identify novel seed longevity genes. We have described 12 novel genes involved in seed longevity. They were found by GWAS and validated by T-DNA insertion mutants. These genes are coding for seed coat TFs, ROS-producing enzymes, a ROSdetoxification enzyme, a mature seed protein, a photosystem component, a cytochrome P-450 and a scaffolding protein. More candidate genes remain to be validated in future studies, increasing the list of genes involved in this highly polygenic trait.

\section{ACKNOWLEDGEMENTS}

This work was funded by grant BIO2017-88898-P from the "Ministerio de Ciencia, Innovación y Universidades," Madrid, Spain. We thank Prof. Julian I. Schroeder and Prof. June M. Kwak (Division of Biological Sciences, University of California at San Diego, La Jolla, USA) for the double mutant rbohd,f; Prof. Graham Noctor (Institute of Plant Sciences Paris-Saclay [IPS2], UMR 9213/UMR1403, Université Paris-Sud, CNRS, INRA, Université d'Evry, Université Paris-Diderot, Sorbonne Paris-Cité, Orsay, France) for the dhar mutants (singles and triple) and Dr. Cristina Ferrándiz (IBMCP, Universitat Politècnica de València-C.S.I.C., Valencia, Spain) for the sep3 and sep1,2,4 mutants.

\section{CONFLICT OF INTEREST}

The authors declare no conflicts of interest.

\section{ORCID}

Joan Renard (D) https://orcid.org/0000-0003-1797-1578

Regina Niñoles (D) https://orcid.org/0000-0002-7862-9509

Irene Martínez-Almonacid (D) https://orcid.org/0000-0002-7342-3632 
Beatriz Gayubas (iD https://orcid.org/0000-0003-4073-6867

Rubén Mateos-Fernández (D) https://orcid.org/0000-0002-1012-7975

Gaetano Bissoli (D) https://orcid.org/0000-0002-5069-1212

Eduardo Bueso (D) https://orcid.org/0000-0002-0828-121X

Ramón Serrano (iD https://orcid.org/0000-0002-4267-0016

José Gadea (iD https://orcid.org/0000-0002-3612-7914

\section{REFERENCES}

Agacka-Mołdoch, M., Nagel, M., Doroszewska, T., Lewis, R. S., \& Börner, A. (2015). Mapping quantitative trait loci determining seed longevity in tobacco (Nicotiana tabacum L.). Euphytica, 202, 479-486. https://doi.org/10.1007/s10681-015-1355-x

Alejandro, S., Rodríguez, P. L., Bellés, J. M., Yenush, L., GarcíaSanchez, M. J., Fernández, J. A., \& Serrano, R. (2007). An Arabidopsis quiescin-sulfhydryl oxidase regulates cation homeostasis at the root symplast-xylem interface. The EMBO Journal, 26, 3203-3215. https:// doi.org/10.1038/sj.emboj.7601757

Andersen, B., Koch, B., \& Scheller, H. V. (1992). Structural and functional analysis of the reducing side of photosystem I. Physiologia Plantarum, 84, 154-161. https://doi.org/10.1111/j.1399-3054.1992.tb08778.x

Atwell, S., Huang, Y. S., Vilhjálmsson, B. J., Willems, G., Horton, M., Li, Y., ... Nordborg, M. (2010). Genome-wide association study of 107 phenotypes in Arabidopsis thaliana inbred lines. Nature, 465, 627-631. https://doi.org/10.1038/nature08800

Bailly, C. (2004). Active oxygen species and antioxidants in seed biology. Seed Science Research, 14, 93-107. https://doi.org/10.1079/ SSR2004159

Bailly, C., El-Maarouf-Bouteau, H., \& Corbineau, F. (2008). From intracellular signaling networks to cell death: The dual role of reactive oxygen species in seed physiology. Comptes Rendus Biologies, 331, 806-814. https://doi.org/10.1016/j.crvi.2008.07.022

Bak, S., Beisson, F., Bishop, G., Hamberger, B., Höfer, R., Paquette, S., \& Werck-Reichhart, D. (2011). Cytochromes P450. The Arabidopsis Book, 9, e0144. https://doi.org/10.1199/tab.0144

Ballesteros, D., \& Walters, C. (2011). Detailed characterization of mechanical properties and molecular mobility within dry seed glasses: Relevance to the physiology of dry biological systems. The Plant Journal, 68, 607-619. https://doi.org/10.1111/j.1365-313X.2011.04711.x

Beisson, F., Li, Y., Bonaventure, G., Pollard, M., \& Ohlrogge, J. B. (2007). The acyltransferase GPAT5 is required for the synthesis of suberin in seed coat and root of Arabidopsis. The Plant Cell, 19, 351-368. https://doi.org/10.1105/tpc.106.048033

Benveniste, I., Tijet, N., Adas, F., Philipps, G., Salaün, J.-P., \& Durst, F. (1998). CYP86A1 from Arabidopsis thaliana encodes a cytochrome P450-dependent fatty acid omega-hydroxylase. Biochemical and Biophysical Research Communications, 243, 688-693. https://doi.org/10. 1006/bbrc.1998.8156

Bhargava, A., Ahad, A., Wang, S., Mansfield, S. D., Haughn, G. W., Douglas, C. J., \& Ellis, B. E. (2013). The interacting MYB75 and KNAT7 transcription factors modulate secondary cell wall deposition both in stems and seed coat in Arabidopsis. Planta, 237, 1199-1211. https:// doi.org/10.1007/s00425-012-1821-9

Brundrett, M. C., Kendrick, B., \& Peterson, C. A. (1991). Efficient lipid staining in plant material with Sudan red $7 \mathrm{~B}$ or fluoral yellow 088 in polyethylene glycol-glycerol. Biotechnic \& Histochemistry, 66, 111-116. https://doi.org/10.3109/10520299109110562

Bueso, E., Muñoz-Bertomeu, J., Campos, F., Brunaud, V., Martínez, L., Sayas, E., ... Serrano, R. (2014). Arabidopsis thaliana HOMEOBOX25 uncovers a role for gibberellins in seed longevity. Plant Physiology, 164, 999-1010. https://doi.org/10.1104/pp.113.232223

Bueso, E., Muñoz-Bertomeu, J., Campos, F., Martínez, C., Tello, C., Martínez-Almonacid, I., ... Serrano, R. (2016). Arabidopsis COGWHEEL1 links light perception and gibberellins with seed tolerance to deterioration. The Plant Journal, 87, 583-596. https://doi.org/10. 1111/tpj.13220

Cao, J., Schneeberger, K., Ossowski, S., Günther, T., Bender, S., Fitz, J., ... Weigel, D. (2011). Whole-genome sequencing of multiple Arabidopsis thaliana populations. Nature Genetics, 43, 956-963. https://doi.org/ 10.1038/ng.911

Chang, Y. L., Li, W. Y., Miao, H., Yang, S. Q., Li, R., Wang, X., ... Chen, K. M. (2016). Comprehensive genomic analysis and expression profiling of the NOX gene families under abiotic stresses and hormones in plants. Genome Biology and Evolution, 8, 791-810. https://doi.org/10.1093/ gbe/evw035

Clerkx, E. J. M., Blankestijn-De Vries, H., Ruys, G. J., Groot, S. P. C., \& Koornneef, M. (2004). Genetic differences in seed longevity of various Arabidopsis mutants. Physiologia Plantarum, 121, 448-461.https://doi. org/10.1111/j.0031-9317.2004.00339.x.

Coen, O., Fiume, E., Xu, W., Vos, D. D., Lu, J., Pechoux, C., ... Magnani, E. (2017). Developmental patterning of the sub-epidermal integument cell layer in Arabidopsis seeds. Development, 144, 1490-1497. https:// doi.org/10.1242/dev.146274

Compagnon, V., Diehl, P., Benveniste, I., Meyer, D., Schaller, H., Schreiber, L., ... Pinot, F. (2009). CYP86B1 is required for very long chain $\omega$-hydroxyacid and $\alpha, \omega$-dicarboxylic acid synthesis in root and seed suberin polyester. Plant Physiology, 150, 1831-1843. https://doi. org/10.1104/pp.109.141408

Curtin, S. J., Tiffin, P., Guhlin, J., Trujillo, D. I., Burghart, L. T., Atkins, P., ... Young, N. D. (2017). Validating genome-wide association candidates controlling quantitative variation in nodulation. Plant Physiology, 173, 921-931. https://doi.org/10.1104/pp.16.01923

Curtis, M. D., \& Grossniklaus, U. (2003). A gateway cloning vector set for high-throughput functional analysis of genes in planta. Plant Physiology, 133, 462-469. https://doi.org/10.1104/pp.103. 027979

Czechowski, T., Stitt, M., Altmann, T., Udvardi, M. K., \& Scheible, W.-R. (2005). Genome-wide identification and testing of superior reference genes for transcript normalization in Arabidopsis. Plant Physiology, 139, 5-17. https://doi.org/10.1104/pp.105.063743

Debeaujon, I., Léon-Kloosterziel, K. M., \& Koornneef, M. (2000). Influence of the testa on seed dormancy, germination, and longevity in Arabidopsis. Plant Physiology, 122, 403-414. https://doi.org/10.1104/pp. 122.2.403

Ditta, G., Pinyopich, A., Robles, P., Pelaz, S., \& Yanofsky, M. F. (2004). The SEP4 gene of Arabidopsis thaliana functions in floral organ and meristem identity. Current Biology, 14, 1935-1940. https://doi.org/10. 1016/j.cub.2004.10.028

Dixon, D. P., Davis, B. G., \& Edwards, R. (2002). Functional divergence in the glutathione transferase superfamily in plants. Identification of two classes with putative functions in redox homeostasis in Arabidopsis thaliana. Journal of Biological Chemistry, 277, 30859-30869. https:// doi.org/10.1074/jbc.M202919200

Dixon, D. P., \& Edwards, R. (2010). Glutathione transferases. The Arabidopsis Book, 2010, e0131. https://doi.org/10.1199/tab.0131

Duan, H., \& Schuler, M. A. (2005). Differential expression and evolution of the Arabidopsis CYP86A subfamily. Plant Physiology, 137, 1067-1081. https://doi.org/10.1104/pp.104.055715

Dubos, C., Stracke, R., Grotewold, E., Weisshaar, B., Martin, C., \& Lepiniec, L. (2010). MYB transcription factors in Arabidopsis. Trends in Plant Science, 15, 573-581. https://doi.org/10.1016/j.tplants.2010. 06.005

Favaro, R., Pinyopich, A., Battaglia, R., Kooiker, M., Borghi, L., Ditta, G., ... Colombo, L. (2003). MADS-box protein complexes control carpel and ovule development in Arabidopsis. The Plant Cell, 15, 2603-2611. https://doi.org/10.1105/tpc.015123

Foyer, C. H., \& Noctor, G. (2011). Ascorbate and glutathione: The heart of the redox hub. Plant Physiology, 155, 2-18. https://doi.org/10.1104/ pp.110.16756 
Gan, X., Stegle, O., Behr, J., Steffen, J. G., Drewe, P., Hildebrand, K. L., ... Mott, R. (2011). Multiple reference genomes and transcriptomes for Arabidopsis thaliana. Nature, 477, 419-423. https://doi.org/10.1038/ nature10414

Gladyshev, V. N. (2014). The free radical theory of aging is dead. Long live the damage theory! Antioxidants \& Redox Signaling, 20(4), 727-731. https://doi.org/10.1089/ars.2013.5228

Goffman, F. D., Alonso, A. P., Schwender, J., Shachar-Hill, Y., \& Ohlrogge, J. B. (2005). Light enables a very high efficiency of carbon storage in developing embryos of rapeseed. Plant Physiology, 138, 2269-2279. https://doi.org/10.1104/pp.105.063628

Golz, J. F., Allen, P. J., Li, S. F., Parish, R. W., Jayawardana, N. U., Bacic, A., \& Doblin, M. S. (2018). Layers of regulation - Insights into the role of transcription factors controlling mucilage production in the Arabidopsis seed coat. Plant Science, 272, 179-192. https://doi.org/10. 1016/j.plantsci.2018.04.021

Grefen, C., Donald, N., Hashimoto, K., Kudla, J., Schumacher, K., \& Blatt, M. R. (2010). A ubiquitin-10 promoter-based vector set for fluorescent protein tagging facilitates temporal stability and native protein distribution in transient and stable expression studies. The Plant Journal, 64, 355-365. https://doi.org/10.1111/j.1365-313X. 2010.04322.x

Grimm, D. G., Roqueiro, D., Salomé, P. A., Kleeberger, S., Greshake, B., Zhu, W., ... Borgwardt, K. M. (2017). easyGWAS: A cloud-based platform for comparing the results of genome-wide association studies. The Plant Cell, 29(1), 5-19. https://doi.org/10.1105/tpc.16.00551

Groot, S. P., Surki, A. A., de Vos, R. C., \& Kodde, J. (2012). Seed storage at elevated partial pressure of oxygen, a fast method for analysing seed ageing under dry conditions. Annals of Botany, 110(6), 1149-1159. https://doi.org/10.1093/aob/mcs198

Haldrup, A., Lunde, C., \& Scheller, H. V. (2003). Arabidopsis thaliana plants lacking the PSI-D subunit of photosystem I suffer severe Photoinhibition, have unstable photosystem I complexes, and altered redox homeostasis in the chloroplast stroma. Journal of Biological Chemistry, 278, 33276-33283. https://doi.org/10.1074/jbc.M305106200

Harman, D. (1956). Aging: A theory based on free radical and radiation chemistry. Journal of Gerontology, 11, 298-300. https://doi.org/10. 1093/geronj/11.3.298

Harman, G. E., \& Mattick, L. R. (1976). Association of lipid oxidation with seed ageing and death. Nature, 260, 323-324. https://doi.org/10. 1038/260323a0

Haughn, G., \& Chaudhury, A. (2005). Genetic analysis of seed coat development in Arabidopsis. Trends in Plant Science, 10, 472-477. https:// doi.org/10.1016/j.tplants.2005.08.005.

Hay, F. R., Valdez, R., Lee, J.-S., \& Cruz, P. C. S. (2019). Seed longevity phenotyping: Recommendations on research methodology. Journal of Experimental Botany, 70, 425-434. https://doi.org/10.1093/jxb/ ery358

Hoekstra, F. A., Golovina, E. A., \& Buitink, J. (2001). Mechanisms of plant desiccation tolerance. Trends in Plant Science, 6, 431-438. https://doi. org/10.1016/S1360-1385(01)02052-0

Höfer, R., Briesen, I., Beck, M., Pinot, F., Schreiber, L., \& Franke, R. (2008). The Arabidopsis cytochrome P450 CYP86A1 encodes a fatty acid omega-hydroxylase involved in suberin monomer biosynthesis. Journal of Experimental Botany, 59(9), 2347-2360. https://doi.org/10.1093/ jxb/ern101

Hooper, C. M., Castleden, I. R., Tanz, S. K., Aryamanesh, N., \& Millar, A. H. (2017). SUBA4: The interactive data analysis centre for Arabidopsis subcellular protein locations. Nucleic Acids Research, 45, D1064-D1074. https://doi.org/10.1093/nar/gkw1041

Horton, M. W., Hancock, A. M., Huang, Y. S., Toomajian, C., Atwell, S., Auton, A., ... Bergelson, J. (2012). Genome-wide patterns of genetic variation in worldwide Arabidopsis thaliana accessions from the RegMap panel. Nature Genetics, 44(2), 212-216. https://doi.org/10.1038/ ng.1042
Hugouvieux, V., Silva, C. S., Jourdain, A., Stigliani, A., Charras, Q., Conn, V., ... Zubieta, C. (2018). Tetramerization of MADS family transcription factors SEPALLATA3 and AGAMOUS is required for floral meristem determinacy in Arabidopsis. Nucleic Acids Research, 46, 4966-4977. https://doi.org/10.1093/nar/gky205

Hundertmark, M., Buitink J., Leprince, O., \& Hincha, D. K. (2011) The reduction of seed-specific dehydrins reduces seed longevity in Arabidopsis thaliana. Seed Science Research, 21, 165-173. https://doi.org/ 10.1017/S0960258511000079

Ihnatowicz, A., Pesaresi, P., Varotto, C., Richly, E., Schneider, A., Jahns, P., ... Leister, D. (2004). Mutants for photosystem I subunit D of Arabidopsis thaliana: Effects on photosynthesis, photosystem I stability and expression of nuclear genes for chloroplast functions. The Plant Journal, 37, 839-852. https://doi.org/10.1111/j.1365-313X.2004.02011.x

International Seed Testing Association (2018). Seed vigour testing. In International rules for seed testing 2018. Bassersdorf, Switzerland: International Seed Testing Association.

loannidis, J., Thomas, G., \& Daly, M. (2009). Validating, augmenting and refining genome-wide association signals. Nature Reviews. Genetics, 10, 318-329. https://doi.org/10.1038/nrg2544

Jaspard, E., Macherel, D., \& Hunault, G. (2012). Computational and statistical analyses of amino acid usage and physico-chemical properties of the twelve late embryogenesis abundant protein classes. PLoS One, 7, e36968. https://doi.org/10.1371/journal.pone.0036968

Jeevan Kumar, S. P., Rajendra Prasad, S., Banerjee, R., \& Thammineni, C. (2015). Seed birth to death: Dual functions of reactive oxygen species in seed physiology. Annals of Botany, 116, 663-668. https://doi.org/ 10.1093/aob/mcv098

Jetha, K., Theißen, G., \& Melzer, R. (2014). Arabidopsis SEPALLATA proteins differ in cooperative DNA-binding during the formation of floral quartet-like complexes. Nucleic Acids Research, 42(17), 10927-10942. https://doi.org/10.1093/nar/gku755

Jiang, W., Lee, J., Jin, Y.-M., Qiao, Y., Piao, R., Jang, S. M., ... Koh, H.-J. (2011). Identification of QTLs for seed germination capability after various storage periods using two RIL populations in rice. Molecules and Cells, 31, 385-392. https://doi.org/10.1007/s10059-011-0049-z

Kai, K., Hashidzume, H., Yoshimura, K., Suzuki, H., Sakurai, N., Shibata, D., \& Ohta, D. (2009). Metabolomics for the characterization of cytochromes P450-dependent fatty acid hydroxylation reactions in Arabidopsis. Plant Biotechnology, 26, 175-182. https://doi.org/10. 5511/plantbiotechnology.26.175

Kannangara, R., Branigan, C., Liu, Y., Penfield, T., Rao, V., Mouille, G., ... Broun, P. (2007). The transcription factor WIN1/SHN1 regulates Cutin biosynthesis in Arabidopsis thaliana. The Plant cell, 19(4), 1278-1294. https://doi.org/10.1105/tpc.106.047076

Korte, A., \& Farlow, A. (2013). The advantages and limitations of trait analysis with GWAS: A review. Plant Methods, 9, 29. https://doi.org/10. 1186/1746-4811-9-29

Kranner, I., Birtić, S., Anderson, K. M., \& Pritchard, H. W. (2006). Glutathione half-cell reduction potential: A universal stress marker and modulator of programmed cell death? Free Radical Biology and Medicine, 40, 2155-2165. https://doi.org/10.1016/j.freeradbiomed.2006.02.013

Landjeva, S., Lohwasser, U., \& Börner, A. (2010). Genetic mapping within the wheat $D$ genome reveals QTL for germination, seed vigour and longevity, and early seedling growth. Euphytica, 171, 129-143. https://doi.org/10.1007/s10681-009-0016-3

Le, B. H., Cheng, C., Bui, A. Q., Wagmaister, J. A., Henry, K. F., Pelletier, J., ... Goldberg, R. B. (2010). Global analysis of gene activity during Arabidopsis seed development and identification of seed-specific transcription factors. Proceedings of the National Academy of Sciences of the United States of America, 107(18), 8063-8070. https://doi.org/10. 1073/pnas.1003530107

Leprince, O., Pellizzaro, A., Berriri, S., \& Buitink, J. (2017). Late seed maturation: Drying without dying. Journal of Experimental Botany, 68, 827-841. https://doi.org/10.1093/jxb/erw363 
Liu, Y., You, S., Taylor-Teeples, M., Li, W. L., Schuetz, M., Brady, S. M., \& Douglas, C. J. (2014). BEL1-LIKE HOMEODOMAIN6 and KNOTTED Arabidopsis thaliana7 interact and regulate secondary cell wall formation via repression of REVOLUTA. The Plant Cell, 26(12), 4843-4861. https://doi.org/10.1105/tpc.114.128322

Long, Q., Rabanal, F. A., Meng, D., Huber, C. D., Farlow, A., Platzer, A., ... Nordborg, M. (2013). Massive genomic variation and strong selection in Arabidopsis thaliana lines from Sweden. Nature Genetics, 45(8), 884-890. https://doi.org/10.1038/ng.2678

López-Otín, C., Galluzzi, L., Freije, J. M. P., Madeo, F., \& Kroemer, G. (2016). Metabolic control of longevity. Cell, 166, 802-821. https://doi. org/10.1016/j.cell.2016.07.031

Lurin, C., Andrés, C., Aubourg, S., Bellaoui, M., Bitton, F., Bruyère, C., ... Small, I. (2004). Genome-wide analysis of Arabidopsis pentatricopeptide repeat proteins reveals their essential role in organelle biogenesis. The Plant Cell, 16(8), 2089-2103. https://doi.org/10. 1105/tpc.104.022236

MacAlister, C., Ohashi-Ito, K., \& Bergmann, D. (2007). Transcription factor control of asymmetric cell divisions that establish the stomatal lineage. Nature, 445, 537-540. https://doi.org/10.1038/nature05491

Mansuy, D. (1998). The great diversity of reactions catalyzed by cytochromes P450. Comparative Biochemistry and Physiology. Part C, Pharmacology, Toxicology \& Endocrinology, 121, 5-14. https://doi.org/10. 1016/s0742-8413(98)10026-9

Marino, D., Dunand, C., Puppo, A., \& Pauly, N. (2012). A burst of plant NADPH oxidases. Trends in Plant Science, 17, 9-15. https://doi.org/ 10.1016/j.tplants.2011.10.001

Merati, G., \& Zanetti, G. (1987). Chemical cross-linking of ferredoxin to spinach thylakoids: Evidence for two independent binding sites of ferredoxin to the membrane. FEBS Letters, 215, 37-40. https://doi.org/ 10.1016/0014-5793(87)80109-6

Miller, G., Shulaev, V., \& Mittler, R. (2008). Reactive oxygen signaling and abiotic stress. Physiologia Plantarum, 133, 481-489. https://doi.org/ 10.1111/j.1399-3054.2008.01090.x

Mizzotti, C., Ezquer, I., Paolo, D., Rueda-Romero, P., Guerra, R. F., Battaglia, R., ... Colombo, L. (2014). SEEDSTICK is a master regulator of development and metabolism in the Arabidopsis seed coat. PLoS Genetics, 10(12), e1004856. https://doi.org/10.1371/journal.pgen.1004856

Murgia, I., Giacometti, S., Balestrazzi, A., Paparella, S., Pagliano, C., \& Morandini, P. (2015). Analysis of the transgenerational iron deficiency stress memory in Arabidopsis thaliana plants. Frontiers in Plant Science, 6, 745. https://doi.org/10.3389/fpls.2015.00745

Murphy, T. M., Asard, H., \& Cross, A. R. (1998). Possible sources of reactive oxygen during the oxidative burst in plants. In $\mathrm{H}$. Asard, A. Berczi, \& R. J. Caubergs (Eds.), Plasma membrane redox systems and their role in biological stress and disease (pp. 215-246). Dordrecht, the Netherlands: Springer Netherlands. https://doi.org/10.1007/978-94-0172695-5_9

Nagel, M., Kodde, J., Pistrick, S., Mascher, M., Börner, A., \& Groot, S. P. (2016). Barley seed aging: Genetics behind the dry elevated pressure of oxygen aging and moist controlled deterioration. Frontiers in Plant Science, 7, 388. https://doi.org/10.3389/fpls.2016.00388

Nagel, M., Seal, C. E., Colville, L., Rodenstein, A., Un, S., Richter, J., ... Kranner, I. (2019). Wheat seed ageing viewed through the cellular redox environment and changes in $\mathrm{pH}$. Free Radical Research, 53, 641-654. https://doi.org/10.1080/10715762.2019.1620226

Nakajima, S., Ito, H., Tanaka, R., \& Tanaka, A. (2012). Chlorophyll b reductase plays an essential role in maturation and storability of Arabidopsis seeds. Plant Physiology, 160(1), 261-273. https://doi.org/10.1104/pp. 112.196881

Nelson, D. R. (1999). Cytochrome P450 and the individuality of species. Archives of Biochemistry and Biophysics, 369, 1-10. https://doi.org/10. 1006/abbi.1999.1352

Nguyen, T.-P., Keizer, P., van Eeuwijk, F., Smeekens, S., \& Bentsink, L. (2012). Natural variation for seed longevity and seed dormancy are negatively correlated in Arabidopsis. Plant Physiology, 160, 2083-2092. https://doi.org/10.1104/pp.112.206649

O'Malley, R. C., \& Ecker, J. R. (2010). Linking genotype to phenotype using the Arabidopsis unimutant collection. The Plant Journal, 61, 928-940. https://doi.org/10.1111/j.1365-313X.2010.04119.x

Oliver, M. J., Tuba, Z., \& Mishler, B. D. (2000). The evolution of vegetative desiccation tolerance in land plants. Plant Ecology, 151, 85-100. https://doi.org/10.1023/A:1026550808557

Pelaz, S., Ditta, G. S., Baumann, E., Wisman, E., \& Yanofsky, M. F. (2000). B and $C$ floral organ identity functions require SEPALLATA MADS-box genes. Nature, 405, 200-203. https://doi.org/10.1038/35012103

Pinnola, A., \& Bassi, R. (2018). Molecular mechanisms involved in plant photoprotection. Biochemical Society Transactions, 46, 467-482. https://doi.org/10.1042/BST20170307

Prieto-Dapena, P., Castaño, R., Almoguera, C., \& Jordano, J. (2006). Improved resistance to controlled deterioration in transgenic seeds. Plant Physiology, 142, 1102-1112. https://doi.org/10.1104/pp.106. 087817

Qu, Y., Yan, M., \& Zhang, Q. (2017). Functional regulation of plant NADPH oxidase and its role in signaling. Plant Signaling \& Behavior, 12(8), e1356970. https://doi.org/10.1080/15592324.2017.1356970

Rahantaniaina, M.-S., Li, S., Chatel-Innocenti, G., Tuzet, A., IssakidisBourguet, E., Mhamdi, A., \& Noctor, G. (2017). Cytosolic and chloroplastic DHARs cooperate in oxidative stress-driven activation of the salicylic acid pathway. Plant Physiology, 174, 956-971. https://doi.org/ 10.1104/pp.17.00317

Rajjou, L., Lovigny, Y., Groot, S. P., Belghazi, M., Job, C., \& Job, D. (2008). Proteome-wide characterization of seed aging in Arabidopsis: A comparison between artificial and natural aging protocols. Plant Physiology, 148(1), 620-641. https://doi.org/10.1104/pp.108.123141

Renard, J., Martínez-Almonacid, I., Sonntag, A., Molina, I., Moya-Cuevas, J., Bissoli, G., ... Bueso, E. (2020). PRX2 and PRX25, peroxidases regulated by COG1, are involved in seed longevity in Arabidopsis. Plant, Cell \& Environment, 43(2), 315-326. https://doi.org/10.1111/pce. 13656

Righetti, K., Vu, J. L., Pelletier, S., Vu, B. L., Glaab, E., Lalanne, D., ... Buitink, J. (2015). Inference of longevity-related genes from a robust coexpression network of seed maturation identifies regulators linking seed storability to biotic defense-related pathways. The Plant Cell, 27, 2692-2708. https://doi.org/10.1105/tpc.15.00632

Romano, J. M., Dubos, C., Prouse, M. B., Wilkins, O., Hong, H., Poole, M., ... Campbell, M. M. (2012). AtMYB61, an R2R3-MYB transcription factor, functions as a pleiotropic regulator via a small gene network. New Phytologist, 195, 774-786. https://doi.org/10.1111/j.1469-8137. 2012.04201.x

Ruuska, S. A., Girke, T., Benning, C., \& Ohlrogge, J. B. (2002). Contrapuntal networks of gene expression during Arabidopsis seed filling. The Plant Cell, 14, 1191-1206. https://doi.org/10.1105/tpc.000877

Sano, N., Rajjou, L., North, H. M., Debeaujon, I., Marion-Poll, A., \& Seo, M. (2016). Staying alive: Molecular aspects of seed longevity. Plant and Cell Physiology, 57, 660-674. https://doi.org/10.1093/pcp/pcv186

Sattler, S. E., Gilliland, L. U., Magallanes-Lundback, M., Pollard, M., \& DellaPenna, D. (2004). Vitamin E is essential for seed longevity and for preventing lipid peroxidation during germination. The Plant Cell, 16, 1419-1432. https://doi.org/10.1105/tpc.021360.

Schindelin, J., Arganda-Carreras, I., Frise, E., Kaynig, V., Longair, M., Pietzsch, T., ... Cardona, A. (2012). Fiji: An open-source platform for biological-image analysis. Nature Methods, 9, 676-682. https://doi. org/10.1038/nmeth.2019

Schmidlin, C. J., Dodson, M. B., Madhavan, L., \& Zhang, D. D. (2019). Redox regulation by NRF2 in aging and disease. Free Radical Biology and Medicine, 134, 702-707. https://doi.org/10.1016/j. freeradbiomed.2019.01.016

Schwember, A. R., \& Bradford, K. J. (2010). Quantitative trait loci associated with longevity of lettuce seeds under conventional and controlled 
deterioration storage conditions. Journal of Experimental Botany, 61, 4423-4436. https://doi.org/10.1093/jxb/erq248

Seren, Ü., Vilhjálmsson, B. J., Horton, M. W., Meng, D., Forai, P., Huang, Y. S., ... Nordborg, M. (2012). GWAPP: A web application for genome-wide association mapping in Arabidopsis. The Plant Cell, 24 (12), 4793-4805. https://doi.org/10.1105/tpc.112.108068

Sharma, M., \& Pandey, G. K. (2016). Expansion and function of repeat domain proteins during stress and development in plants. Frontiers in Plant Science, 6, 1218. https://doi.org/10.3389/fpls.2015.01218

Smirnoff, N. (2011). Chapter 4 - Vitamin C: The metabolism and functions of ascorbic acid in plants. In F. Rébeillé \& R. Douce (Eds.), Advances in botanical research, 59, 107-177. Academic Press. London, Waltham, San Diego and Amsterdam. https://doi.org/10.1016/B978-0-12385853-5.00003-9

Soza, V. L., Snelson, C. D., Hewett Hazelton, K. D., \& Di Stilio, V. S. (2016). Partial redundancy and functional specialization of E-class SEPALLATA genes in an early-diverging eudicot. Developmental Biology, 419, 143-155. https://doi.org/10.1016/j.ydbio.2016.07.021

Suzuki, N., Miller, G., Morales, J., Shulaev, V., Torres, M. A., \& Mittler, R. (2011). Respiratory burst oxidases: The engines of ROS signaling. Current Opinion in Plant Biology, 14, 691-699. https://doi.org/10.1016/j.pbi.2011.07.014

Torres, M. A., Dangl, J. L., \& Jones, J. D. G. (2002). Arabidopsis gp91phox homologues AtrbohD and AtrbohF are required for accumulation of reactive oxygen intermediates in the plant defense response. Proceedings of the National Academy of Sciences, 99, 517-522. https://doi.org/ 10.1073/pnas.012452499

Vertucci, C. W., \& Roos, E. E. (1990). Theoretical basis of protocols for seed storage. Plant Physiology, 94(3), 1019-1023. https://doi.org/10. 1104/pp.94.3.1019

Wang, J., Zhang, H., \& Allen, R. D. (1999). Overexpression of an Arabidopsis Peroxisomal ascorbate peroxidase gene in tobacco increases protection against oxidative stress. Plant and Cell Physiology, 40, 725-732. https://doi.org/10.1093/oxfordjournals.pcp.a029599

Watson, C. J. W., Froehlich, J. E., Josefsson, C. A., Chapple, C., Durst, F., Benveniste, I., \& Coolbaugh, R. C. (2001). Localization of CYP86B1 in the outer envelope of chloroplasts. Plant and Cell Physiology, 42, 873-878. https://doi.org/10.1093/pcp/pce110

Weigel, D. (2012). Natural variation in Arabidopsis: From molecular genetics to ecological genomics. Plant Physiology, 158(1), 2-22. https://doi. org/10.1104/pp.111.189845
Wellesen, K., Durst, F., Pinot, F., Benveniste, I., Nettesheim, K., Wisman, E., ... Yephremov, A. (2001). Functional analysis of the LACERATA gene of Arabidopsis provides evidence for different roles of fatty acid $\omega$-hydroxylation in development. Proceedings of the National Academy of Sciences, 98, 9694-9699. https://doi.org/10. 1073/pnas.171285998

Winter, D., Vinegar, B., Nahal, H., Ammar, R., Wilson, G. V., \& Provart, N. J. (2007). An "electronic fluorescent pictograph" browser for exploring and analyzing large-scale biological data sets. PLoS One, 2(8), e718. https://doi.org/10.1371/journal.pone.0000718

Wood, A. J., \& Jenks, M. A. (2008). Plant desiccation tolerance: Diversity, distribution, and real-world application. M.A. Jenks \& A. J. Wood In Plant desiccation tolerance (pp. 1-10). Ames: Blackwell Publishing. https://doi.org/10.1002/9780470376881.ch1

Xie, H.-T., Wan, Z.-Y., Li, S., \& Zhang, Y. (2014). Spatiotemporal production of reactive oxygen species by NADPH oxidase is critical for Tapetal programmed cell death and pollen development in Arabidopsis. The Plant Cell, 26, 2007-2023. https://doi.org/10.1105/tpc.114.125427

Yadav, V., Molina, I., Ranathunge, K., Castillo, I. Q., Rothstein, S. J., \& Reed, J. W. (2014). ABCG transporters are required for suberin and pollen wall extracellular barriers in Arabidopsis. The Plant Cell, 26, 3569-3588. https://doi.org/10.1105/tpc.114.129049

Zilber, A. L., \& Malkin, R. (1988). Ferredoxin cross-links to a $22 \mathrm{kD}$ subunit of photosystem I. Plant Physiology, 88, 810-814. https://doi.org/10. 1104/pp.88.3.810

\section{SUPPORTING INFORMATION}

Additional supporting information may be found online in the Supporting Information section at the end of this article.

How to cite this article: Renard J, Niñoles R, MartínezAlmonacid I, et al. Identification of novel seed longevity genes related to oxidative stress and seed coat by genome-wide association studies and reverse genetics. Plant Cell Environ. 2020;43:2523-2539. https://doi.org/10.1111/pce.13822 